\title{
BANK LIABILITIES CHANNEL
}

\author{
Vincenzo Quadrini* \\ University of Southern California and CEPR
}

February 4, 2015

\begin{abstract}
The financial intermediation sector is important not only for channeling resources from agents in excess of funds to agents in need of funds (lending channel). By issuing liabilities it also creates financial assets held by other sectors of the economy for insurance purpose. When the intermediation sector creates less liabilities or their value falls, agents are less willing to engage in activities that are individually risky but desirable in aggregate (bank liabilities channel). The paper studies how financial crises driven by self-fulfilling expectations are transmitted, through this channel, to the real sector of the economy.
\end{abstract}

${ }^{*}$ I would like to thank Satyajit Chatterjee for an insightful discussion and seminar participants at Bank of Mexico, Bank of Portugal, Boston College, Carlos III University, Cemfi, Cheung Kong Graduate School of Business, Federal Reserve Board, Istanbul school of Central Banking, ITAM Mexico, NOVA University in Lisbon, Purdue University, Shanghai University of Finance and Economics, University of Maryland, University of Melbourne, University of Notre Dame, University of Pittsburgh, UQAM in Montreal. 


\section{Introduction}

There is a well established tradition in macroeconomics that adds financial market frictions to standard macroeconomic models. The seminal work of Bernanke and Gertler (1989) and Kiyotaki and Moore (1997) are the classic references for most of the work done in this area during the last three decades. Although these contributions differ in many details ranging from the micro-foundation of market incompleteness to the scope of the application, they typically share two common features. The first is that the role played by financial frictions in the propagation of shocks to the real sector of the economy is based on the 'credit channel'. The idea is that various shocks can affect the financing capability of borrowers - either in the available credit or in the cost - which in turn affects their economic decisions (consumption, investment, employment, etc.).

The second feature of these models is that they assign a limited role to the financial intermediation sector. This is not to say that there are not studies that emphasize the role of banks for the aggregate economy. Holmstrom and Tirole (1997) provided a theoretical foundation for the central roles of banks in general equilibrium, inspiring subsequent contributions such as Van den Heuvel (2008) and Meh and Moran (2010). However, it is only after the recent crisis that the role of financial intermediaries became central to the research agenda in macroeconomics. Recent contributions include Adrian, Colla, and Shin (2013), Boissay, Collard, and Smets (2010), Brunnermeier and Sannikov (2010), Corbae and D'Erasmo (2012), De Fiore and Uhlig (2011), Gertler and Karadi (2011), Gertler and Kiyotaki (2010), Mendoza and Quadrini (2010), Rampini and Viswanathan (2012).

In most of these studies, the primary role of the intermediation sector is to channel funds to borrowers. Because of frictions, the funds intermediated depends on the financial conditions of banks. When these conditions deteriorate, the volume of intermediated funds declines, which in turn forces borrowers to cut investments and other economic activities. Therefore, the primary channel through which financial intermediation affects real economic activity is still the typical 'credit or lending channel'. The goal of this paper is to emphasize an additional, possibly complementary, channel called 'bank liabilities channel'.

The importance of the financial intermediation sector is not limited to channeling resources from agents in excess of funds to agents in need of funds (credit channel). By issuing liabilities, it also creates financial assets 
that can be held by other sectors of the economy for insurance purposes. When the supply or the value of bank liabilities decline, the holders of these liabilities (being them households or firms) are less willing to engage in activities that are individually risky because of lower insurance, with negative macroeconomic effects.

The channel can be illustrated with an example. Suppose that a bank issues 1 dollar liability and sells it to agent $A$. The dollar is then used by the bank to make a loan to agent $B$. By doing so the bank facilitates a more efficient allocation of resources because, typically, agent $B$ is in a condition to create more value than agent $A$ (because of higher productivity or higher marginal utility of consumption). However, if the bank is unable or unwilling to issue the dollar liability, it will not make the loan and, as a consequence, agent $B$ is forced to cut investment and/or consumption. This illustrates the standard 'credit or lending channel' of financial intermediation.

In addition to the credit channel just described, when the bank issues the 1 dollar liability, it creates a financial asset that will be held by agent $A$. For this agent, the bank liability represents a financial asset that can be used to insure the uncertain outcome of various economic activities including investment, hiring, consumption. Then, when the holdings of bank liabilities decline, agent $A$ is discouraged from engaging in economic activities that are individually risky but desirable in aggregate. Therefore, it is through the supply of bank liabilities that the financial intermediation sector also plays an important role for the real sector of the economy.

The example illustrates the insurance role played by financial intermediaries in a simple fashion: issuance of traditional bank deposits. However, the complexity of assets and liabilities issued by the intermediation sector has grown over time and many of these activities are important for providing insurance. In some cases, the assets and liabilities issued by the financial sector do not involve significant intermediation of funds in the current period but create the conditions for future payments as in the case of derivatives. In other cases, intermediaries simply facilitate the direct issuance of liabilities by non-financial sectors as in the case of public offering of corporate bonds and shares or the issuance of mortgage-backed securities. Even though these securities do not remain in the portfolio of financial firms, banks still play an important role in facilitating the creation of these securities and, later on, in affecting their value in the secondary market. Corporate mergers and acquisitions can also be seen in this logic since, in addition to promote operational efficiency, they also allow for corporate diversification (i.e., insurance). Still, 
the direct involvement of banks is crucial for the success of these operations. Therefore, even if many financial assets held by the nonfinancial sector are directly created in the nonfinancial sector (this is the case, for example, for government and corporate bonds), financial intermediaries still play a central role for the initial issuance and later for the functioning of the secondary market. This motivates the focus of the paper on the creation of financial assets by financial firms that are not limited to commercial banks.

Another goal of this paper is to explore a possible mechanism that affects the value of bank liabilities. The mechanism is based on self-fulfilling expectations about the liquidity in the financial intermediation sector: when the market expects the intermediation sector to be liquid, banks have the capability of issuing additional liabilities and, therefore, they are liquid. On the other hand, when the market expects the intermediation sector to be illiquid, banks are unable to issue additional liabilities and, as a result, they end up being illiquid. Through this mechanism the model could generate multiple equilibria: a 'good' equilibrium characterized by expanded financial intermediation, sustained economic activity and high asset prices, and a 'bad' equilibrium characterized by reduced financial intermediation, lower economic activity and depressed asset prices. A financial crisis takes place when the economy switches from a good equilibrium to a bad equilibrium.

The existence of multiple equilibria and, therefore, the emergence of a crisis is possible only when banks are highly leveraged. This implies that structural changes that increase the incentives of banks to take on more leverage create the conditions for greater financial and macroeconomic instability. In the application of the model I will consider two trends that may have increased the incentive of banks to take on more leverage: the growth of emerging economies and financial innovations.

Emerging countries tend to accumulate safe assets issued by industrialized countries. As the world market share of these countries increases, so does the world demand for safe assets with subsequent decline in the equilibrium interest rate. The lower interest rate reduces the funding cost of banks and increases their incentive to leverage. The higher leverage, however, could make multiple equilibria possible, exposing the economy to financial crises.

Financial innovation is another mechanism that could induce banks to take more leverage. In the model financial innovation is captured by a reduction in the operation cost to raise funds. This reduces the funding cost encouraging banks to leverage more. On the one hand, this facilitates higher financial intermediation and expanded economic activity. On the other, how- 
ever, it creates the conditions for the emergence of a crisis and/or for amplifying the consequences of a crisis.

The organization of the paper is as follows. Section 2 describes the theoretical framework and characterizes the equilibrium. Section 3 applies the model to study how the growth of emerging countries and financial innovations have affected the stability of the macro-economy. Section 4 concludes.

\section{$2 \quad$ Model}

There are three sectors: the entrepreneurial sector, the worker sector and the financial intermediation sector. The role of the financial intermediation sector is to facilitate the transfer of resources between entrepreneurs and workers. In the process of intermediating funds, however, financial intermediaries might have an incentive to leverage which could create the conditions for financial and macroeconomic instability.

I describe first the entrepreneurial and worker sectors. After characterizing the equilibrium with direct borrowing and lending between these two sectors, I introduce the financial intermediation sector under the assumption that direct borrowing and lending is not possible or efficient.

\subsection{Entrepreneurial sector}

In the entrepreneurial sector there is a unit mass of entrepreneurs, indexed by $i$, with lifetime utility $\mathbb{E}_{0} \sum_{t=0}^{\infty} \beta^{t} \ln \left(c_{t}^{i}\right)$. Entrepreneurs are individual owners of firms, each operating the production function $y_{t}^{i}=z_{t}^{i} h_{t}^{i}$, where $h_{t}^{i}$ is the input of labor supplied by workers at the market wage $w_{t}$, and $z_{t}^{i}$ is an idiosyncratic productivity shock. The productivity shock is independently and identically distributed among firms and over time, with probability distribution $\Gamma(z)$. As in Arellano, Bai, and Kehoe (2011), the input of labor $h_{t}^{i}$ is chosen before observing $z_{t}^{i}$, and therefore, labor is risky.

Entrepreneurs have access to a market for non-contingent bonds with gross interest rate $R_{t}^{b}$. The bonds held by entrepreneurs are the liabilities issued by banks and specified later.

An entrepreneur $i$ enters period $t$ with bonds $b_{t}^{i}$ and chooses the labor input $h_{t}^{i}$. After the realization of the idiosyncratic shock $z_{t}^{i}$, he/she chooses consumption $c_{t}^{i}$ and next period bonds $b_{t+1}^{i}$. The budget constraint is

$$
c_{t}^{i}+\frac{b_{t+1}^{i}}{R_{t}^{b}}=\left(z_{t}^{i}-w_{t}\right) h_{t}^{i}+b_{t}^{i}
$$


Because labor $h_{t}^{i}$ is chosen before the realization of $z_{t}^{i}$, while the saving decision is made after the observation of $z_{t}^{i}$, it will be convenient to define $a_{t}^{i}=b_{t}^{i}+\left(z_{t}^{i}-w_{t}\right) h_{t}^{i}$ the entrepreneur's wealth after production. Given the timing structure, the input of labor $h_{t}^{i}$ depends on $b_{t}^{i}$ while the saving choice $b_{t+1}^{i}$ depends on $a_{t}^{i}$. The optimal entrepreneur's policies are characterized by the following lemma:

Lemma 2.1 Let $\phi_{t}$ satisfy the condition $\mathbb{E}_{z}\left\{\frac{z-w_{t}}{1+\left(z-w_{t}\right) \phi_{t}}\right\}=0$. The optimal entrepreneur's policies are

$$
\begin{aligned}
h_{t}^{i} & =\phi_{t} b_{t}^{i}, \\
c_{t}^{i} & =(1-\beta) a_{t}^{i}, \\
\frac{b_{t+1}^{i}}{R_{t}^{b}} & =\beta a_{t}^{i} .
\end{aligned}
$$

Proof 2.1 See Appendix A.

The demand for labor is linear in the initial wealth of the entrepreneur $b_{t}^{i}$. The term of proportionality $\phi_{t}$ is defined by condition $\mathbb{E}_{z}\left\{\frac{z-w_{t}}{1+\left(z-w_{t}\right) \phi_{t}}\right\}=$ 0 , where the expectation is over the idiosyncratic shock $z$ with probability distribution $\Gamma(z)$. Since the only endogenous variable that affects $\phi_{t}$ is the wage rate, I will denote this term by the function $\phi\left(w_{t}\right)$. It can be verified that this function is strictly decreasing in $w_{t}$.

Because $\phi\left(w_{t}\right)$ is the same for all entrepreneurs, I can derive the aggregate demand for labor as

$$
H_{t}=\phi\left(w_{t}\right) \int_{i} b_{t}^{i}=\phi\left(w_{t}\right) B_{t}
$$

where capital letters denote average (per-capita) variables. The aggregate demand depends negatively on the wage rate - which is a standard propertyand positively on the financial wealth of entrepreneurs - which is a special property of this model. This derives from the fact that labor is risky and entrepreneurs are willing to hire labor only if they hold financial wealth for consumption smoothing.

Also linear is the consumption policy which follows from the logarithmic specification of the utility function. This property allows for linear aggregation. Another property worth emphasizing is that in a stationary equilibrium 
with constant $B_{t}$, the interest rate must be lower than the intertemporal discount rate, ${ }^{1}$ that is, $R^{b}<1 / \beta-1$.

\subsection{Worker sector}

There is a unit mass of workers with lifetime utility $\mathbb{E}_{0} \sum_{t=0}^{\infty} \beta^{t}\left(c_{t}-\alpha \frac{h_{t}^{1+\frac{1}{\nu}}}{1+\frac{1}{\nu}}\right)$, where $c_{t}$ is consumption and $h_{t}$ is the supply of labor. Workers do not face idiosyncratic risks and the assumption of risk neutrality is not important for the key results of the paper as will be discussed later.

Each worker holds a non-reproducible asset available in fixed supply $\bar{K}$, with each unit producing $\chi$ units of consumption goods. The asset is divisible and can be traded at the market price $p_{t}$. We can think of the asset as housing and $\chi$ as the services produced by one unit of housing. Workers can borrow at the gross interest rate $R_{t}^{l}$ and face the budget constraint

$$
c_{t}+l_{t}+\left(k_{t+1}-k_{t}\right) p_{t}=\frac{l_{t+1}}{R_{t}^{l}}+w_{t} h_{t}+\chi k_{t},
$$

where $l_{t}$ is the loan contracted in period $t-1$ and due in the current period $t$, and $l_{t+1}$ is the new debt that will be repaid in the next period $t+1$.

Debt is constrained by a borrowing limit. I will consider two specifications. In the first specification the borrowing limit takes the form

$$
l_{t+1} \leq \eta
$$

where $\eta$ is constant. Later I will consider a borrowing constraint that depends on the collateral value of assets, that is,

$$
l_{t+1} \leq \eta \mathbb{E}_{t} p_{t+1} k_{t+1}
$$

The borrowing constraint (2) allows me to characterize the equilibrium analytically. However, the asset price $p_{t}$ is constant. With the borrowing

\footnotetext{
${ }^{1}$ To see this, consider the first order condition of an individual entrepreneur for the choice of $b_{t+1}^{i}$. This is the typical euler equation that, with log preferences, takes the form $1 / c_{t}^{i}=\beta R^{b} \mathbb{E}_{t}\left(1 / c_{t+1}^{i}\right)$. Because individual consumption $c_{t+1}^{i}$ is stochastic, $\mathbb{E}_{t}\left(1 / c_{t+1}^{i}\right)>$ $1 / \mathbb{E}_{t} c_{t+1}^{i}$. Therefore, if $\beta R^{b}=1$, we would have that $\mathbb{E}_{t} c_{t+1}^{i}>c_{t}^{i}$, implying that individual consumption would growth on average. But then aggregate consumption would not be bounded, which violates the hypothesis of a stationary equilibrium. I will come back to this property later.
} 
constraint (3), instead, the model also provides interesting predictions about the asset price $p_{t}$ but the full characterization of the equilibrium can be done only numerically.

Appendix C writes down the workers' problem and derives the first order conditions. When the borrowing constraint takes the form specified in (2), the optimality conditions are

$$
\begin{aligned}
\alpha h_{t}^{\frac{1}{\nu}} & =w_{t} \\
1 & =\beta R_{t}^{l}\left(1+\mu_{t}\right), \\
p_{t} & =\beta \mathbb{E}_{t}\left(\chi+p_{t+1}\right),
\end{aligned}
$$

where $\beta \mu_{t}$ is the Lagrange multiplier associated with the borrowing constraint. When the borrowing constraint takes the form specified in (3), only the first order condition with respect to $k_{t+1}$ differs, taking the form

$$
p_{t}=\beta \mathbb{E}_{t}\left[\chi+\left(1+\eta \mu_{t}\right) p_{t+1}\right]
$$

\subsection{Equilibrium with direct borrowing and lending}

Before introducing the financial intermediation sector it would be instructive to characterize the equilibrium with direct borrowing and lending. In this case the bonds held by entrepreneurs are equal to the loans taken by workers and market clearing implies $R_{t}^{b}=R_{t}^{l}=R_{t}$.

Proposition 2.1 In absence of aggregate shocks, the economy converges to a steady state in which workers borrow from entrepreneurs and $\beta R<1$.

Proof 2.1 See Appendix B

The fact that the steady state interest rate is lower than the intertemporal discount rate is a consequence of the uninsurable risk faced by entrepreneurs. If $\beta R=1$, entrepreneurs would continue to accumulate bonds without limit in order to insure the idiosyncratic risk. The supply of bonds from workers, however, is limited by the borrowing constraint of workers. To insure that entrepreneurs do not accumulate an infinite amount of bonds, the interest rate has to fall below the intertemporal discount rate.

The equilibrium in the labor market can be characterized as the simple intersection of aggregate demand and supply as depicted in Figure 1. The 
aggregate demand was derived in the previous subsection and takes the form $H_{t}^{D}=\phi\left(w_{t}\right) B_{t}$. It depends negatively on the wage rate $w_{t}$ and positively on the aggregate wealth (bonds) of entrepreneurs, $B_{t}$. The supply is derived from the households' first order condition (4) and takes the form $H_{t}^{S}=\left(\frac{w_{t}}{\alpha}\right)^{\nu}$.

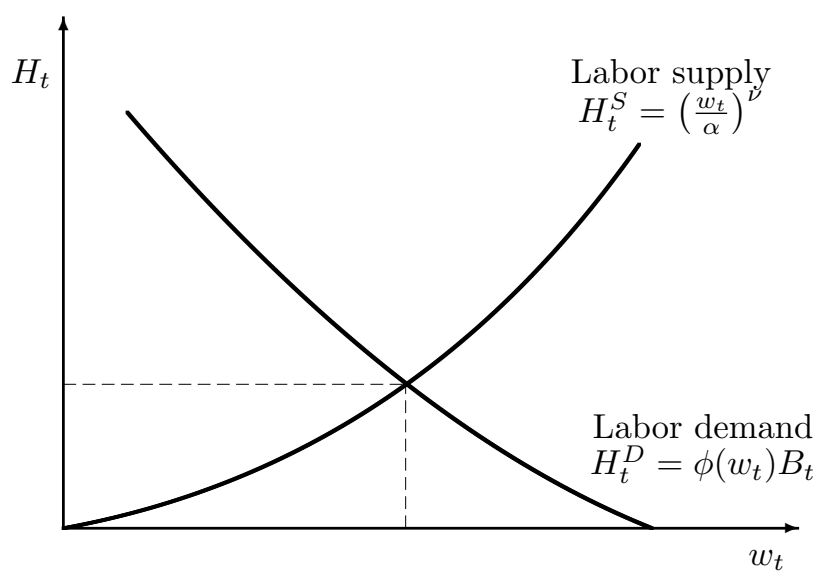

Figure 1: Labor market equilibrium.

The dependence of the demand of labor from the financial wealth of entrepreneurs is a key property of this model. When entrepreneurs hold a lower value of $B_{t}$, the demand for labor declines and in equilibrium there is lower employment and production. Importantly, the reason lower values of $B_{t}$ decreases the demand of labor is not because employers do not have funds to finance hiring or because they face a higher financing cost. In fact, employers do not need any financing to hire and produce. Instead, the transmission mechanism is based on the lower financial wealth of entrepreneurs which is held as an insurance buffer against the idiosyncratic risk. This mechanism is clearly distinct from the traditional 'credit channel' where firms are in need of funds to finance employment (for example, because wages are paid in advance) or to finance investment.

The next step is to introduce financial intermediaries and show that a fall in $B_{t}$ could be the result of a crisis that originates in the financial sector.

Discussion In the equilibrium described above, producers (entrepreneurs) are net savers while workers are net borrowers. Since it is customary to work with models in which firms are net borrowers (for example in the studies referenced in the introduction), this property may seem counterfactual. 
This financial structure, however, is not inconsistent with the recent changes observed in the United States.

It is well known that during the last two and half decades, US corporations have increased their holdings of financial assets. As shown in Figure 2, the net financial assets - that is, the difference between financial assets and liabilities - have become positive in the 2000s for the nonfinancial corporate sector. The only exception is at the pick of the 2008 crisis when the financial assets held by corporations declined in value. Therefore, recent evidence shows that US corporations are no longer net borrowers in aggregate.

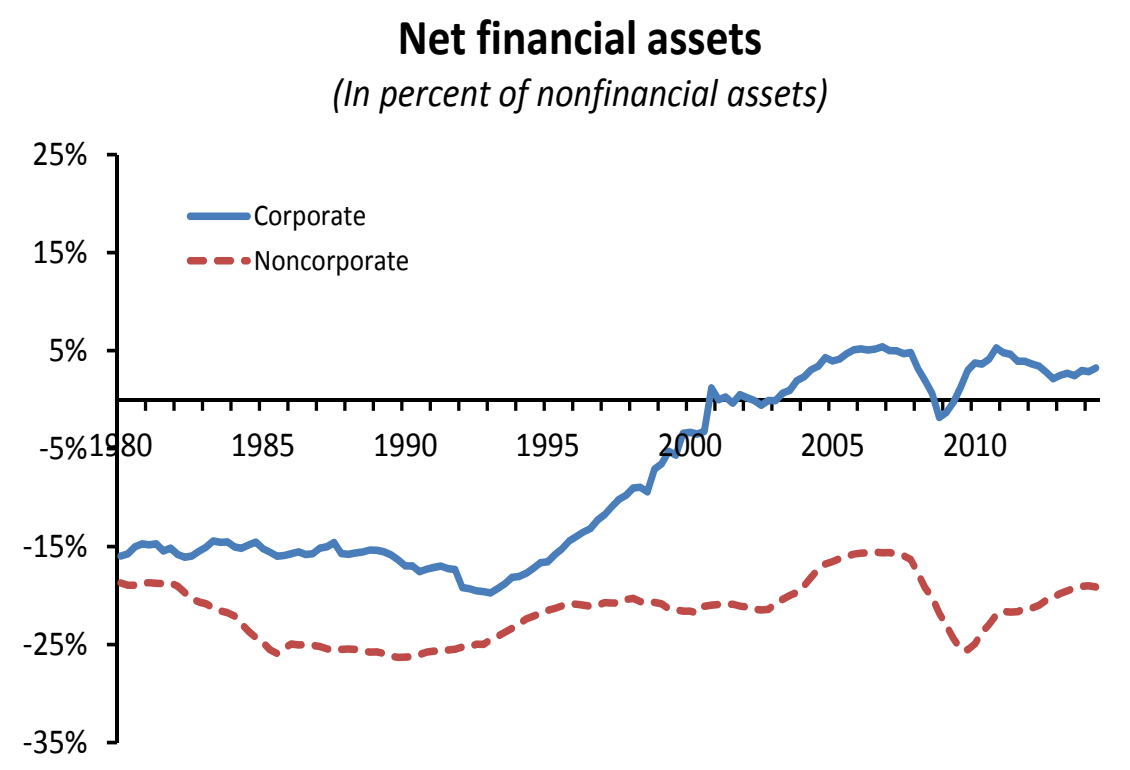

Figure 2: Net financial assets (assets minus liabilities) in the nonfinancial business sector as a percentage of nonfinancial assets. Source: Flows of Funds Accounts.

The reversal from net borrower to net lender did not arise in the noncorporate sector. The net financial assets of the noncorporate sector remained negative, without any particular upward or downward trend. Still, the change experienced by the corporate sector shows that a large segment of the business sector is no longer dependent on external financing. ${ }^{2}$ Of course, these are just aggregate numbers and, possibly, there is significant heterogeneity.

\footnotetext{
${ }^{2}$ If we aggregate the corporate sector with the noncorporate sector, the overall net borrowing remains positive but has declined dramatically from about 20 percent in the early nineties to about 5 percent.
} 
However, these numbers suggest that the proportion of financially dependent firms has declined significantly over time. This pattern is shown in more details in Shourideh and Zetlin-Jones (2012) using data from the Flows of Funds and firm level data from Compustat. Also related is Eisfeldt and Muir (2012) showing that there is a strong correlation between the funds raised externally by corporations and their accumulation of liquid financial assets (suggesting that raising external funds does not necessarily increase the net financial liabilities of firms). The model developed here is meant to capture the growing importance of firms that are no longer dependent on external financing.

The second remark relates to the statement that firms are not dependent on external financing if they hold positive net financial assets. This definition of external dependence is purely static and captures the idea that a firm is capable of increasing spending in the current period only if it has the option of borrowing more. Similarly, a firm is financially independent if it can increase its current spending without the need of borrowing. This definition of financial independence, however, does not guarantee that a firm is financially independent in the future. Negative shocks could reduce the financial wealth of entrepreneurs and force them to cut future consumption (or dividends). Still, this is different from traditional models with financial constraints on firms. In these models, the financial mechanism affects the production and investment decisions of firms in important ways only when they are financially constrained in the period in which these decisions are made. More specifically, only when the current multiplier associated with the borrowing constraint becomes positive.

The third remark is that the equilibrium outcome of having the entrepreneurial sector to be a net lender does not derive from the assumption that entrepreneurs are more risk-averse than workers. Instead, it follows from the assumption that only entrepreneurs are exposed to uninsurable risks. As long as producers face more risk than workers, the former would continue to lend to the latter even if workers were risk averse.

The final remark relates to the assumption that the idiosyncratic risk faced by entrepreneurs cannot be insured away (market incompleteness). Given that workers are risk neutral, it would be optimal for entrepreneurs to offer a wage that is contingent on the output of the firm. Although this is excluded by assumption, it is not difficult to extend the model so that the lack of insurance from workers is an endogenous outcome of information asymmetries. The idea is that, when the wage is state-contingent, firms could 
use their information advantage about the performance of the firm to gain opportunistically from workers. The same argument can be used to justify more generally the absence of a market for contingent claims. Since this is well known in the literature, I decided to impose the absence of an insurance market for idiosyncratic risks by assumption.

\subsection{Financial intermediation sector}

If direct borrowing is not feasible or inefficient, financial intermediaries becomes important for transferring funds from lenders (entrepreneurs) to borrowers (workers) and to create financial assets that could be held for insurance purposes. It is under this assumption that I introduce the financial intermediation sector.

There is a continuum of infinitely lived banks owned by workers. Even if I use the term 'banks' as a reference to financial intermediaries, it should be clear that the financial sector in the model is representative of all financial firms, not only traditional commercial banks. The assumption that banks are held by workers, as opposed to entrepreneurs, makes the analysis simpler because workers are risk neutral while entrepreneurs are risk averse.

Banks start the period with loans made to workers, $l_{t}$, and liabilities held by entrepreneurs, $b_{t}$. The difference between loans and liabilities is the bank equity $e_{t}=l_{t}-b_{t}$.

Given the beginning of period balance sheet position, the bank could default on its liabilities. In case of default creditors have the right to liquidate the bank assets $l_{t}$. However, they may not recover the full value of the assets. In particular, with probability $\lambda$ creditors recover only a fraction $\underline{\xi}<1$.

It will be convenient to define the variable $\xi_{t} \in\{\underline{\xi}, 1\}$ as the fraction of the bank assets recovered by creditors in the event of default. The recovery value can then be written more generally as $\xi_{t} l_{t}$. Therefore, with probability $\lambda$ creditors recover $\xi l_{t}$ and with probability $1-\lambda$ they recover the full value $l_{t}$. The variable $\xi_{t}$ is the same for all banks (aggregate stochastic variable) and its value is unknown when the bank issued the liabilities $b_{t}$ and made the loans $l_{t}$ in period $t-1$.

The recovery fraction $\xi_{t}$ will be derived endogenously in the model. For the moment, however, it will be convenient to think of $\xi_{t}$ as an exogenous stochastic variable.

Once $\xi_{t} \in\{\xi, 1\}$ becomes known at the beginning of period $t$, the bank could use the threat of default to renegotiate the outstanding liabilities. As- 
suming that the bank has the whole bargaining power, the liabilities can be renegotiated to $\xi_{t} l_{t}$. Therefore, after renegotiation, the residual liabilities of the bank are

$$
\tilde{b}_{t}\left(b_{t}, l_{t}\right)= \begin{cases}b_{t}, & \text { if } b_{t} \leq \xi_{t} l_{t} \\ \xi_{t} l_{t} & \text { if } b_{t}>\xi_{t} l_{t}\end{cases}
$$

Renegotiation, however, is costly for a bank. More specifically, in case of renegotiation the bank incurs the cost

$$
\tilde{\varphi}_{t}\left(b_{t+1}, l_{t}\right)=\left\{\begin{array}{ll}
0, & \text { if } b_{t} \leq \xi_{t} l_{t} \\
\varphi\left(\frac{b_{t}-\xi_{t} l_{t}}{l_{t}}\right) b_{t} & \text { if } b_{t}>\xi_{t} l_{t}
\end{array} .\right.
$$

The function $\varphi($.$) is strictly increasing and convex, differentiable and satisfies$ $\varphi(0)=\varphi^{\prime}(0)=0$. Furthermore, I assume that $\varphi(1-\underline{\xi})<1-\underline{\xi}$. This property guarantees that the gain from renegotiation (which happens when $b_{t}>\xi_{t} l_{t}$ ) is always positive for the bank. ${ }^{3}$

The possibility of renegotiation implies potential losses for investors (entrepreneurs), which are fully internalized by the market when the bank issues the new liabilities $b_{t+1}$ and makes the new loans $l_{t+1}$.

Denote by $\bar{R}_{t}^{b}$ the expected gross return on the market portfolio of bank liabilities issued in period $t$ and repaid in period $t+1$ (expected return on liabilities issued by the whole banking sector). Since banks are atomistic and the sector is competitive, the expected return on the liabilities issued by an individual bank must be equal to the aggregate expected return $\bar{R}_{t}^{b}$. Therefore, the price of liabilities $q_{t}\left(b_{t+1}, l_{t+1}\right)$ issued by an individual bank at $t$ must satisfy

$$
q_{t}\left(b_{t+1}, l_{t+1}\right) b_{t+1}=\frac{1}{\bar{R}_{t}^{b}} \mathbb{E}_{t} \tilde{b}_{t+1}\left(b_{t+1}, l_{t+1}\right) .
$$

The left-hand-side is the payment made by investors (entrepreneurs) for

\footnotetext{
${ }^{3}$ Banks do not borrow more than $l_{t}$ because this will trigger renegotiation with probability 1. Therefore, renegotiation can only arise when $\xi_{t}=\xi$. Provided that $b_{t}>\xi l_{t}$, the debt reduction from renegotiating is $b_{t}-\xi l_{t}$. This is a gain that is compared to the cost $\varphi\left(b_{t} / l_{t}-\xi\right) b_{t}$. Suppose that $b_{t}=l_{t}$ (maximum leverage). In this case the gain from renegotiation is $l_{t}-\xi l_{t}$ while the cost is $\varphi(1-\xi) b_{t}$. Since $b_{t}<l_{t}$, we can verify that the gain is bigger than the cost if $\varphi(1-\underline{\xi})<1-\underline{\xi}$. The concavity of $\varphi($.$) implies that this is$ also true when the bank chooses a leverage smaller than the maximum, that is, $b_{t}<l_{t}$.
} 
the purchase of $b_{t+1}$. The term on the right-hand-side is the expected repayment in the next period, discounted by $\bar{R}_{t}^{b}$ (the expected market return).

The final assumption is that banks incur an operation cost $\tau$ per unit of raised funds. This parameter captures the efficiency of the intermediation sector. Later, in the application of the model, I will interpret changes in $\tau$ as the result of financial innovations.

The budget constraint of the bank, after renegotiation, can be written as

$$
\tilde{b}_{t}\left(b_{t}, l_{t}\right)+\tilde{\varphi}_{t}\left(b_{t}, l_{t}\right)+\frac{l_{t+1}}{R_{t}^{l}}+d_{t}=l_{t}+(1-\tau)\left[\frac{\mathbb{E}_{t} \tilde{b}_{t+1}\left(b_{t+1}, l_{t+1}\right)}{\bar{R}_{t}^{b}}\right] \text {, }
$$

where $d_{t}$ are the dividends paid to shareholders (workers) and the functions $\tilde{b}_{t}\left(b_{t}, l_{t}\right)$ and $\tilde{\varphi}_{t}\left(b_{t}, l_{t}\right)$ are defined in $(8)$ and $(9)$. The last term in the budget constraint denotes the funds raised by issuing new liabilities $b_{t+1}$. According to equation (10), these funds are equal to $\mathbb{E}_{t} \tilde{b}_{t+1}\left(b_{t+1}, l_{t+1}\right) / \bar{R}_{t}^{b}$. They are multiplied by $1-\tau$ because of the operation cost.

The problem solved by the bank can be written recursively as

$$
V_{t}\left(b_{t}, l_{t}\right)=\max _{d_{t}, b_{t+1}, l_{t+1}}\left\{d_{t}+\beta \mathbb{E}_{t} V_{t+1}\left(b_{t+1}, l_{t+1}\right)\right\}
$$

subject to (8), (9), (11).

The decision to renegotiate existing liabilities is implicitly accounted by the functions $\tilde{b}_{t}\left(b_{t}, l_{t}\right)$ and $\tilde{\varphi}_{t}\left(b_{t}, l_{t}\right)$. The leverage cannot exceed 1 since in this case the bank would renegotiate with certainty. Once the probability of renegotiation is 1 , a further increase in $b_{t+1}$ does not increase the borrowed funds $\left[(1-\tau) / \bar{R}_{t}^{b}\right] \mathbb{E}_{t} \tilde{b}_{t+1}\left(b_{t+1}, l_{t+1}\right)$ but raises the renegotiation cost. Therefore, Problem (12) is also subject to the constraint $b_{t+1} \leq l_{t+1}$.

The optimal policies of the bank are characterized by the first order conditions with respect to $b_{t+1}$ and $l_{t+1}$. Denote by $\omega_{t+1}=b_{t+1} / l_{t+1}$ the bank leverage. The first order conditions, derived in Appendix D, take the form

$$
\begin{aligned}
\frac{1-\tau}{\bar{R}_{t}^{b}} \geq \beta\left[1+\frac{\theta\left(\omega_{t+1}\right)\left(\varphi^{\prime}\left(\omega_{t+1}-\underline{\xi}\right) \omega_{t+1}+\varphi\left(\omega_{t+1}-\underline{\xi}\right)\right)}{1-\theta\left(\omega_{t+1}\right)}\right] \\
\frac{1}{\bar{R}_{t}^{l}} \geq \beta\left[1+\theta\left(\omega_{t+1}\right) \varphi^{\prime}\left(\omega_{t+1}-\underline{\xi}\right) \omega_{t+1}^{2}+\theta\left(\omega_{t+1}\right) \underline{\xi}\left(\frac{1-\tau}{\beta \bar{R}_{t}^{b}}-1\right)\right]
\end{aligned}
$$


where the inequality sign applies if $\omega_{t+1}=1$. The variable $\theta\left(\omega_{t+1}\right)$ is the probability that the bank renegotiates at $t+1$, defined as

$$
\theta\left(\omega_{t+1}\right)= \begin{cases}0, & \text { if } \quad \omega_{t+1}<\underline{\xi} \\ \lambda, & \text { if } \quad \underline{\xi} \leq \omega_{t+1} \leq 1 \\ 1, & \text { if } \quad \omega_{t+1}>1\end{cases}
$$

The first conditions make clear that it is the leverage of the bank $\omega_{t+1}=$ $b_{t+1} / l_{t+1}$ that matters, not the scale of operation $b_{t+1}$ or $l_{t+1}$. This follows from the linearity of the intermediation technology and the risk neutrality of banks. The leverage matters because the renegotiation cost is convex in the leverage. These properties imply that in equilibrium all banks choose the same leverage (although they could chose different scales of operation).

Because the first order conditions (13) and (14) depend only on one individual variable, the leverage $\omega_{t+1}$, there is no guarantee that these conditions are both satisfied for arbitrary values of $\bar{R}_{t}^{b}$ and $R_{t}^{l}$. In the general equilibrium, however, these rates adjust to clear the markets for bank liabilities and loans and both conditions will be satisfied.

Further exploration of the first order conditions reveals that, if banks choose a low leverage, that is, $\omega_{t+1}<\underline{\xi}$, then the cost of liabilities (including the operation cost) and the lending rate must be equal to the discount rate, that is, $\bar{R}_{t}^{b} /(1-\tau)=R_{t}^{l}=1 / \beta$. However, if banks choose $\omega_{t+1}>\underline{\xi}$, the funding cost $\bar{R}_{t}^{b} /(1-\tau)$ must be smaller than the interest rate on loans. This is necessary to cover the renegotiation cost incurred with probability $\lambda$.

Lemma 2.2 If the leverage is $\omega_{t+1} \leq \underline{\xi}$, then $\frac{\bar{R}_{t}^{b}}{1-\tau}=R_{t}^{l}=\frac{1}{\beta}$. If the leverage is $\omega_{t+1}>\underline{\xi}$, then $\frac{\bar{R}_{t}^{b}}{1-\tau}<R_{t}^{l}<\frac{1}{\beta}$.

Proof 2.2 See Appendix E

Therefore, once the leverage of banks exceeds $\underline{\xi}$, there is a spread between the funding rate (inclusive of the operation cost $\tau$ ) and the lending rate. Intuitively, raising the leverage $\omega_{t+1}$ above $\underline{\xi}$ increases the expected renegotiation cost. The bank will choose to do so only if there is a spread between the cost of funds and the return on the investment. As the spread 
increases so does the leverage chosen by banks. As we will see, the spread increases when there is more demand for banks liabilities (for example from emerging countries) or the operation cost $\tau$ declines (due, for example, to financial innovations). As the leverage increases above $\xi$, banks could default with positive probability. This generates a loss of financial wealth for entrepreneurs, causing a macroeconomic contraction through the 'bank liabilities channel' as described earlier.

\subsection{Banking liquidity and endogenous $\xi_{t}$}

To make $\xi_{t}$ endogenous, I now interpret this variable as the liquidation price of bank assets. This price will be determined in equilibrium and the liquidity of the whole banking sector plays a central role in determining this price.

Assumption 1 If a bank is liquidated, the assets $l_{t}$ are divisible and can be sold either to other banks or to other sectors (workers and entrepreneurs). However, other sector can recover only a fraction $\underline{\xi}<1$.

Therefore, in the event of liquidation, it is more efficient to sell the liquidated assets to other banks since they have the ability to recover the whole asset value $l_{t}$ while other sectors can recover only $\underline{\xi} l_{t}$. This is a natural assumption since banks have, supposedly, a comparative advantage in the management of financial investments. However, even if it is more efficient to sell the liquidated assets to banks, for this to happen they need to have the liquidity to purchase the assets.

Assumption 2 Banks can purchase the assets of a liquidated bank only if they are liquid, that is, $b_{t}<\xi_{t} l_{t}$.

A bank is liquid if it can issue new liabilities at the beginning of the period without renegotiating. Obviously, if the bank starts with $b_{t}>\xi_{t} l_{t}$ - that is, the liabilities are greater that the liquidation value of its assets - the bank will be unable to raise additional funds: potential investors know that the new liabilities (as well as the outstanding liabilities) are not collateralized and the bank will renegotiate immediately after receiving the funds. ${ }^{4}$

\footnotetext{
${ }^{4}$ Similar assumptions are made in Perri and Quadrini (2011) in a model without banks.
} 
To better understand these assumptions, consider the condition for not renegotiating, $b_{t} \leq \xi_{t} l_{t}$, where now $\xi_{t} \in\{\xi, 1\}$ is the liquidation price of bank assets at the beginning of the period. If this condition is satisfied, banks have the option to raise additional funds at the beginning of the period to purchase the assets of a defaulting bank. This insures that the market price of the liquidated assets is $\xi_{t}=1$. However, if $b_{t}>\xi_{t} l_{t}$ for all banks, there will not be any bank with unused credit. As a result, the liquidated assets can only be sold to non-banks and the price will be $\xi_{t}=\underline{\xi}$. Therefore, the value of liquidated assets depends on the financial decision of banks, which in turn depends on the expected liquidation value of their assets. This interdependence creates the conditions for multiple self-fulfilling equilibria.

Proposition 2.2 There exists multiple equilibria if and only if the leverage of the bank is within the two liquidation prices, that $i s, \underline{\xi} \leq \omega_{t} \leq 1$.

Proof 2.2 See appendix F.

Given the multiplicity, I assume that the equilibrium selection takes place stochastically through sunspot shocks. Denote by $\varepsilon$ a variable that takes the value of zero with probability $\lambda$ and 1 with probability $1-\lambda$. The probability of a low liquidation price, denoted by $\theta\left(\omega_{t}\right)$, is equal to

$$
\theta\left(\omega_{t}\right)= \begin{cases}0, & \text { if } \quad \omega_{t}<\underline{\xi} \\ \lambda, & \text { if } \quad \underline{\xi} \leq \omega_{t} \leq 1 \\ 1, & \text { if } \quad \omega_{t}>1\end{cases}
$$

If the leverage is sufficiently small $\left(\omega_{t}<\underline{\xi}\right)$, banks do not renegotiate even if the liquidation price is low. But then the price cannot be low since banks remain liquid for any expectation of the liquidation price $\xi_{t}$ and, therefore, for any draw of the sunspot variable $\varepsilon$. Instead, when the leverage is between the two liquidation prices $\left(\xi \leq \omega_{t} \leq 1\right)$, the liquidity of banks depends on the expectation of this price. Therefore, the equilibrium outcome depends on the realization of the sunspot variable $\varepsilon$. When $\varepsilon=0-$ which happens with probability $\lambda$-the market expects the low liquidation price $\xi_{t}=\underline{\xi}$, making the banking sector illiquid. On the other hand, when $\varepsilon=1-$ which happens with probability $1-\lambda$-the market expects the high liquidation price $\xi_{t}=1$ so that the banking sector remains liquid. The dependence of the probability $\theta\left(\omega_{t}\right)$ on the leverage of the banking sector plays an important role for the results of this paper. 


\subsection{General equilibrium}

To characterize the general equilibrium I first derive the aggregate demand for bank liabilities from the optimal saving of entrepreneurs. I then derive the supply by consolidating the demand of loans from workers with the optimal policy of banks. In this section I assume that the borrowing limit for workers takes the simpler form specified in (2), which allows me to characterize the equilibrium analytically.

Demand for bank liabilities As shown in Lemma 2.1, the optimal saving of entrepreneurs takes the form $b_{t+1}^{i} / R_{t}^{b}=\beta a_{t}^{i}$, where $a_{t}^{i}$ is the end-of-period wealth $a_{t}^{i}=\tilde{b}_{t}^{i}+\left(z_{t}^{i}-w_{t}\right) h_{t}^{i}$. The lemma was derived under the assumption that the bonds purchased by the entrepreneurs were not risky, that is, entrepreneurs receive $b_{t+1}$ units of consumption goods with certainty in the next period $t+1$. In the extension with financial intermediation, however, bank liabilities are risky since banks may renege on their liabilities. Thanks to the logarithmic utility, however, Lemma 2.1 also holds when the saving instrument is risky. ${ }^{5}$

Since $h_{t}^{i}=\phi\left(w_{t}\right) \tilde{b}_{t}^{i}$ (see Lemma 2.1), the end-of-period wealth can be rewritten as $a_{t}^{i}=\left[1+\left(z_{t}^{i}-w_{t}\right) \phi\left(w_{t}\right)\right] \tilde{b}_{t}^{i}$. Substituting into the optimal saving and aggregating over all entrepreneurs we obtain

$$
B_{t+1}=\beta R_{t}^{b}\left[1+\left(\bar{z}-w_{t}\right) \phi\left(w_{t}\right)\right] \tilde{B}_{t} .
$$

This equation defines the aggregate demand for bank liabilities as a function of the interest rate $R_{t}^{b}$, the wage rate $w_{t}$, and the beginning-of-period aggregate wealth of entrepreneurs $\tilde{B}_{t}$. Remember that the tilde sign denotes the financial wealth of entrepreneurs after the renegotiation of banks. Also notice that $R_{t}^{b}$ is not the expected return from bank liabilities since banks will repay $b_{t+1}$ in full only with some probability.

Using the equilibrium condition in the labor market, we can express the wage rate as a function of $\tilde{B}_{t}$. In particular, equalizing the demand for labor, $H_{t}^{D}=\phi\left(w_{t}\right) \tilde{B}_{t}$, to the supply from workers, $H_{t}^{S}=\left(w_{t} / \alpha\right)^{\nu}$, the wage $w_{t}$ becomes a function of only $\tilde{B}_{t}$. We can then use this function to replace $w_{t}$ in (15) and express the demand for bank liabilities as a function of only $\tilde{B}_{t}$ and $R_{t}^{b}$. This takes the form

$$
B_{t+1}=s\left(\tilde{B}_{t}\right) R_{t}^{b},
$$

\footnotetext{
${ }^{5}$ The proof requires only a trivial extension of the proof of Lemma 2.1 and is omitted.
} 
where $s\left(\tilde{B}_{t}\right)$ is strictly increasing in the wealth of entrepreneurs $\tilde{B}_{t}$.

Figure 3 plots this function for a given value of $\tilde{B}_{t}$. As we change $\tilde{B}_{t}$, the slope of the demand function changes. More specifically, keeping the interest rate constant, higher initial wealth $\tilde{B}_{t}$ implies higher demand for $B_{t+1}$.

Supply of bank liabilities The supply of bank liabilities is derived from consolidating the borrowing decisions of workers with the investment and funding decisions of banks.

According to Lemma 2.2, when banks are highly leveraged, that is, $\omega_{t+1}>$ $\underline{\xi}$, the interest rate on loans must be smaller than the intertemporal discount rate $\left(R_{t}^{l}<1 / \beta\right)$. From the workers' first order condition (5) we can see that $\mu_{t}>0$ if $R_{t}^{l}<1 / \beta$. Therefore, the borrowing constraint for workers is binding, which implies $L_{t+1}=\eta$. Since $B_{t+1}=\omega_{t+1} L_{t+1}$, the supply of bank liabilities is then $B_{t+1}=\eta \omega_{t+1}$.

When the lending rate is equal to the intertemporal discount rate, instead, the demand for loans from workers is undetermined, which in turn implies indeterminacy in the supply of bank liabilities. In this case the liabilities of banks are demand determined. In summary, the supply of bank liabilities is

$$
B^{s}\left(\omega_{t+1}\right)=\left\{\begin{array}{lll}
\text { Undetermined, } & \text { if } & \omega_{t+1}<\underline{\xi} \\
\eta \omega_{t+1}, & \text { if } & \omega_{t+1} \geq \underline{\xi}
\end{array}\right.
$$

So far I have derived the supply of bank liabilities as a function of the bank leverage $\omega_{t+1}$. However, the leverage of banks also depends on the cost of borrowing $\bar{R}_{t}^{b} /(1-\tau)$ through condition (13). The average expected return on bank liabilities for investors, $\bar{R}_{t}^{b}$, is in turn related to the interest rate $R_{t}^{b}$ by the condition

$$
\bar{R}_{t}^{b}=\left[1-\theta\left(\omega_{t+1}\right)+\theta\left(\omega_{t+1}\right)\left(\frac{\underline{\xi}}{\omega_{t+1}}\right)\right] R_{t}^{b}
$$

With probability $1-\theta\left(\omega_{t+1}\right)$ banks do not renegotiate and the ex-post return is $R_{t}^{b}$. With probability $\theta\left(\omega_{t+1}\right)$, however, banks renegotiate and investors recover only a fraction $\underline{\xi} / \omega_{t+1}$ of the initial investment. Therefore, when banks renegotiate, the actual return is $\left(\underline{\xi} / \omega_{t+1}\right) R_{t}^{b}$.

Using (18) to replace $\bar{R}_{t}^{b}$ in equation (13) I obtain a function that relates the interest rate $R_{t}^{b}$ to the leverage of banks $\omega_{t+1}$. Finally, I combine this 
function with $B_{t+1}=\eta \omega_{t+1}$ to obtain the supply of bank liabilities as a function of $R_{t}^{b}$.

Figure 3 plots the supplies of bank liabilities which is undetermined when the interest rate is equal to $(1-\tau) / \beta$ and strictly decreasing for lower values of the interest rate until it reaches $\eta$.

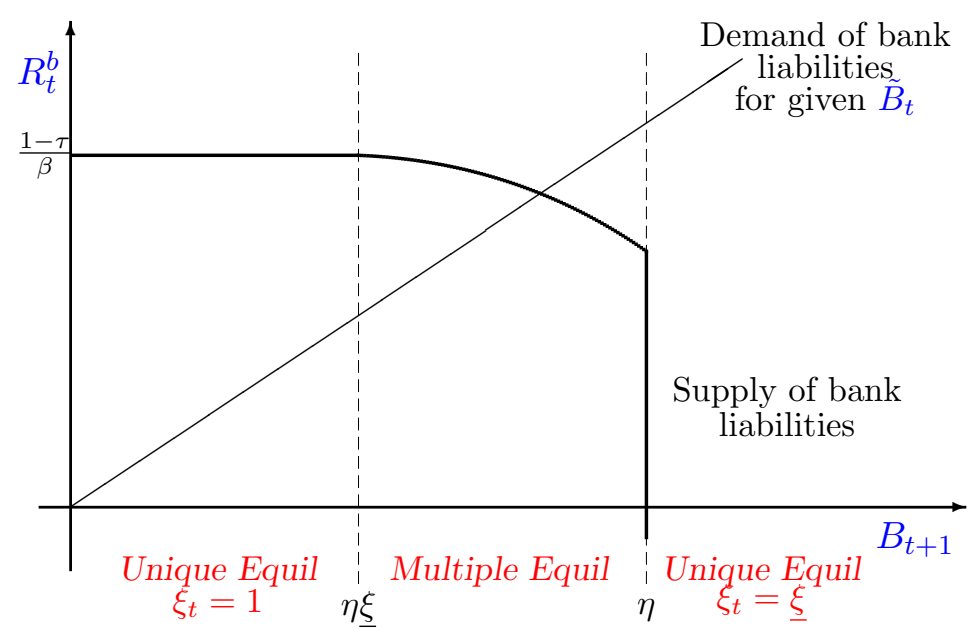

Figure 3: Demand and supply of bank liabilities.

Equilibrium The general equilibrium is characterized by the intersection of the demand and supply of bank liabilities as plotted in Figure 3. The supply (from banks) is decreasing in the funding rate $R_{t}^{b}$ while the demand (from entrepreneurs) is increasing in $R_{t}^{b}$. The demand is plotted for a particular value of outstanding post-renegotiation liabilities $\tilde{B}_{t}$. By changing the outstanding liabilities, the slope of the demand function changes.

The figure also indicates the regions with unique or multiple equilibria. When the interest rate is $(1-\tau) / \beta$, banks are indifferent in the choice of leverage $\omega_{t+1} \leq \underline{\xi}$. When the funding rate falls below this value, however, the optimal leverage starts to increase above $\underline{\xi}$ and the economy enters in the region with multiple equilibria. Once the leverage reaches $\omega_{t+1}=1$, a further decline in the interest rate paid by banks on their liabilities does not lead to higher leverages since the choice of $\omega_{t+1}>1$ would cause renegotiation with probability $1 .^{6}$

\footnotetext{
${ }^{6}$ The dependence of the existence of multiple equilibria from the leverage of the economy
} 
Given the initial entrepreneurial wealth $\tilde{B}_{t}$, the intersection of demand and supply of bank liabilities determines the interest rate $R_{t}^{b}$, which in turn determines the next period wealth of entrepreneurs $\tilde{B}_{t+1}$. In absence of renegotiation we have $\tilde{B}_{t+1}=B_{t+1}$, where $B_{t+1}$ is determined by equation (16). In the event of renegotiation (assuming that we are in a region with multiple equilibria) we have $\tilde{B}_{t+1}=\left(\underline{\xi} / \omega_{t+1}\right) B_{t+1}$. The new $\tilde{B}_{t+1}$ will determine a new slope for the demand of bank liabilities, and therefore, new equilibrium values of $R_{t}^{b}$ and $B_{t+1}$. Depending on the parameters, the economy may or may not reach a steady state. A key parameter determining the convergence to a steady state is the intermediation $\operatorname{cost} \tau$.

Proposition 2.3 There exists $\hat{\tau}>0$ such that: If $\tau \geq \hat{\tau}$, the economy converges to a steady state without renegotiation. If $\tau<\hat{\tau}$, the economy never converges to a steady state but switches stochastically between equilibria with and without renegotiation depending to the realization of the sunspot $\varepsilon$.

Proof 2.3 See Appendix G

In order to converge to a steady state, the economy has to reach an equilibrium in which renegotiation never arises. This can happen only if the interest rate paid on bank liabilities is equal to $R_{t}^{b}=(1-\tau) / \beta$. With this interest rate banks do not have incentive to leverage because the funding cost is equal to the return on loans. For this to be an equilibrium, however, the demand for bank liabilities must be sufficiently low which cannot be the case when $\tau=0$. With $\tau=0$, in fact, the steady state interest rate must be equal to $1 / \beta$. But then entrepreneurs continue to accumulate bank liabilities without bound for precautionary reasons. The demand for bank liabilities will eventually become bigger than the supply (which is bounded by the borrowing constraint of workers), driving the interest rate below $1 / \beta$. As the interest rate falls, multiple equilibria become possible.

Bank leverage and crises Figure 3 illustrates how the type of equilibria depends on the bank leverage. When banks increase their leverage, the economy switches from a state in which the equilibrium is unique (no crises) to a state with multiple equilibria (and the possibility of financial crises). But even if the economy was already in a state with multiple equilibria, the increase in leverage implies that the consequences of a crisis are bigger. In

is also a feature of the sovereign default model of Cole and Kehoe (2000). 
fact, when the economy switches from a good equilibria to a bad equilibria, the bank liabilities are renegotiated to $\eta \xi$. Therefore, bigger are the liabilities issued by banks and larger are the losses incurred by entrepreneurs holding these liabilities. Larger financial losses incurred by entrepreneurs then imply larger declines in the demand for labor, which in turn cause larger macroeconomic contractions. In the next section I will examine two recent trends that may have increased the incentives of banks to take more leverage.

\section{Recent trends and macroeconomic stability}

In this section I use the model to study the impact of two recent trends: the growth of emerging economies (Subsection 3.1) and financial innovation (Subsection 3.2). For the analysis of these two trends I will use the version of the model with the borrowing limit specified in 3. As discussed earlier, this specification of the borrowing constraint implies that the price of the fixed asset changes endogenously over time. This allows me to study how the two trends affect the dynamics of asset prices. The numerical procedure used to solve the model is described in Appendix $\mathrm{H}$.

Before describing how the model is used to study the two trends, I describe the parametrization. The period in the model is a quarter and the discount factor is set to $\beta=0.9825$, implying an annual intertemporal discount rate of about $7 \%$. The parameter $\nu$ in the utility function of workers is the elasticity of the labor supply. I set this elasticity to 3 , which is in the range of values used in macroeconomic models. The utility parameter $\alpha$ is chosen to have an average working time of 0.3 .

The average productivity of entrepreneurs is normalized to $\bar{z}=1$. Since the average input of labor is 0.3 , the average production is also 0.3. The supply of the fixed asset is normalized to $\bar{k}=1$ and its production flow is set to $\chi=0.05$. Total production is the sum of entrepreneurial production $(0.3)$ plus the production from the fixed asset (0.05). Therefore, total production is 0.35 per quarter (about 1.4 per year).

The parameter $\eta$ determines the fraction of the fixed asset that can be used as a collateral. This is set to 0.6. The productivity shock follows a truncated normal distribution with standard deviation of 0.3. Given the baseline parametrization, this implies that the standard deviation of entrepreneurial wealth is about $7 \%$.

The last set of parameters pertain to the banking sector. The low value of $\xi$ is set to $\underline{\xi}=0.75$. The probability that the sunspot variable $\varepsilon$ takes the 
value of zero (which could lead to a bank crisis) is set to 2 percent $(\lambda=0.02)$. Therefore, provided that the economy is in a region that admits multiple equilibria, a crisis arises on average every fifty quarters. The renegotiation cost is assumed to be quadratic, that is, $\varphi()=.(.)^{2}$. Finally, the operation cost for banks is set to $\tau=0.0045$.

Wage flexibility The key channel through which a banking crisis is transmitted to the real sector of the economy is through the demand of labor. To show the importance of wage rigidity I also compare the baseline economy with flexible wages (baseline) to an alternative economy where wages are downward rigid. In this alternative economy wages are perfectly flexible only when the demand of labor induces an increase in the wage or a moderate decline. More specifically, given $w_{t-1}$ the equilibrium wage in the previous period $t-1$, the current wage $w_{t}$ must satisfy $w_{t} \geq \rho w_{t-1}$. The coefficient $\rho$ determines the degree of downward rigidity. With $\rho=1$ wages never decline. With $\rho=0$ wages are perfectly flexible.

Denote by $\bar{w}_{t}$ the wage rate that equalizes the demand and supply of labor, that is, $\phi_{t}\left(\bar{w}_{t}\right) \tilde{B}_{t}=\left(\frac{\bar{w}_{t}}{\alpha}\right)^{\nu}$. Equilibrium employment is always equal to the demand, $H_{t}=\phi_{t}\left(w_{t}\right) \tilde{B}_{t}$, with the wage rate given by

$$
w_{t}= \begin{cases}\bar{w}_{t}, & \text { if } \bar{w}_{t} \geq \rho w_{t-1} \\ \rho w_{t-1}, & \text { if } \bar{w}_{t}<\rho w_{t-1}\end{cases}
$$

In the simulation of the model with rigid wages I set $\rho=0.9999$.

\subsection{The growth of emerging countries}

During the last three decades we have witnessed an unprecedent growth of emerging countries. As a result of the sustained growth, the size of these economies has increased dramatically compared to industrialized countries. The top panel of Figure 4 shows that, in PPP terms, the GDP of emerging countries was less 46 percent the GDP of industrialized countries at the beginning of the 1990s. This number increased to about 90 percent by 2011 . When the GDP comparison is based on nominal exchange rates, the relative size of the emerging economies increased from 17 to 52 percent.

During the same period we have observed an increase in the foreign holding of safe assets by emerging countries. It is customary to divide foreign 


\section{GDP of Emerging Countries over Industrialized Countries}

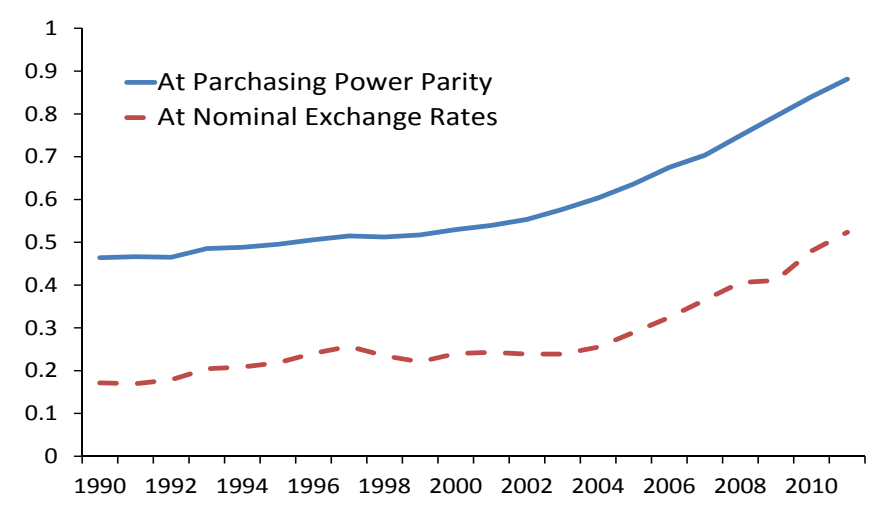

\section{Net Foreign Position in Debt and Reserves (Percent of GDP)}

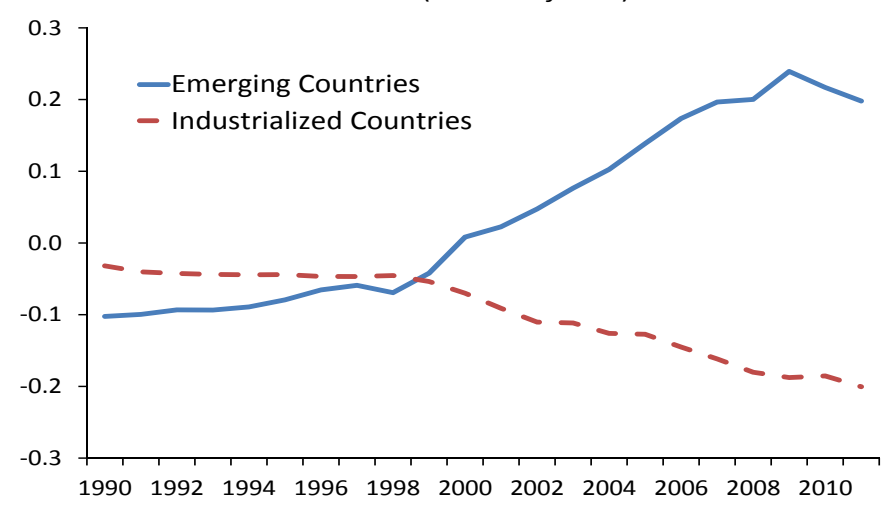

Figure 4: Gross domestic product and net foreign positions in debt instruments and international reserves of emerging and industrialized countries. Emerging countries: Argentina, Brazil, Bulgaria, Chile, China, Hong.Kong, Colombia, Estonia, Hungary, India, Indonesia, South Korea, Latvia, Lithuania, Malaysia, Mexico, Pakistan, Peru, Philippines, Poland, Romania, Russia, South Africa, Thailand, Turkey, Ukraine, Venezuela. Industrialized countries: Australia, Austria, Belgium, Canada, Denmark, Finland, France, Germany, Greece, Ireland, Italy, Japan, Netherlands, New Zealand, Norway, Portugal, Spain, Sweden, Switzerland, United.Kingdom, United.States. Sources: World Development Indicators (World Bank) and External Wealth of Nations Mark II database (Lane and Milesi-Ferretti (2007)).

assets in four classes: (i) debt instruments and international reserves; (ii) portfolio investments; (iii) foreign direct investments; (iv) other investments. 
See Gourinchas and Rey (2007) and Lane and Milesi-Ferretti (2007). The first class of assets - debt and international reserves - are typically considered safer. The net foreign position for emerging and industrialized countries is plotted in the bottom panel of Figure 4.

As can be seen, emerging countries have accumulated 'positive' net positions while industrialized countries have accumulated 'negative' net positions. Therefore, the increase in the relative size of emerging economies has been associated with a significant accumulation by these countries of safer financial assets issued by industrialized countries. The goal of this section is to study how the increased demand for safe assets has affected financial and macroeconomic stability in industrialized countries. ${ }^{7}$

Extended model and numerical simulation To study how the increased demand for safe assets has affected the stability of the globalized economy, I extend the model by assuming that in addition to the demand for bank liabilities from domestic entrepreneurs, there is also a demand for these liabilities from the foreign sector. To keep the model simple, the foreign demand is purely exogenous and, therefore, is insensitive to the equilibrium interest rate. ${ }^{8}$

Denoting by $B_{t}^{D}$ the domestic demand and by $B_{t}^{F}$ the foreign demand, the total demand for bank liabilities is equal to $B_{t}=B_{t}^{D}+B_{t}^{F}$. The renego-

\footnotetext{
${ }^{7}$ There are several theories proposed in the literature to explain why emerging countries have accumulated safer assets issued by industrialized countries. One explanation is based on the view that emerging countries have pursued policies aimed at keeping their currencies undervalued relatively to the currencies of industrialized countries. Another explanation is based on differences in the characteristics of financial markets in emerging and industrialized countries. The idea is that lower financial development in emerging economies impairs the ability of these countries to create viable saving instruments for intertemporal smoothing (Caballero, Farhi, and Gourinchas (2008)) or for insurance purpose (Mendoza, Quadrini, and Ríos-Rull (2009)). Because of this, emerging economies turn to industrialized countries to purchase these assets. A third explanation is based on a higher idiosyncratic uncertainty faced by consumers and firms in emerging countries due, for example, to the greater idiosyncratic risk associated with fast structural changes or lower safety nets provided by the public sector. The goal of this section is not to explore these explanations but to study the consequences for macroeconomic stability.

${ }^{8}$ This approach allows me to study the macroeconomic dynamics in industrial countries but not in emerging economies. The extension to a two-country set-up would also allow me to study how a crisis that originates in industrial countries gets transmitted to emerging countries through international banking. Kalemli-Ozcana, Papaioannou, and Perri (2013) find that these links could be important for cross-country macroeconomic co-movement.
} 
tiation condition for banks remains $B_{t}>\xi_{t} L_{t}$. Besides this, the structure of the economy and the equilibrium conditions are the same as in the closedeconomy model studied earlier.

In the quantitative exercise I assume that the model is representative of the industrialized countries and I interpret the negative of the foreign position in debt and foreign reserves of these countries as the exogenous foreign demand for liabilities coming from emerging economies. ${ }^{9}$

The net position in debt and foreign reserves is shown in Figure 4 for the period 1990-2011. Before 1990, I assume that the net position is constant at the 1990 level, that is, $-3.2 \%$ of GDP. Then, during the subsequent period 1991-2011, it follows the exact pattern shown in the data. Since the period in the model is a quarter while the data on net foreign asset positions is available annually, the inter-quarter values are assumed to be equal to the annual levels. Then, starting in 2012, I assume that the net position remains at the 2011 level, that is, $-20 \%$ of GDP. I assume further that until 1990, the growth in the external demand for bank liabilities is not anticipated. Starting in 1991, however, the future path is perfectly predicted.

Given the parameter values described above, I simulate the model for 2,000 quarters (500 years). In the first 1,000 quarters the foreign demand for bank liabilities is fixed at the 1990 level and agents do not anticipate the future growth in demand. Starting at quarter 1,001 (which corresponds to the first quarter of 1991) agents learn that the foreign demand has changed and will continue to change during the next 80 quarters (from 1991 to 2011) after which it stabilizes at the level observed in 2011.

Numerical results The only aggregate shock in the model is the sunspot shock which takes the value of zero with a 2 percent probability. To better illustrate the stochastic nature of the economy, I repeat the simulation of the model 1,000 times (with each simulation performed over 2,000 periods as described above). Each repeated simulation is based on a sequence of 2,000 random draws of the sunspot shock.

Figure 5 plots the average as well as the 5 th and 95 th percentiles of the 1,000 repeated simulations for each quarter over the period 1981-2020. This corresponds to periods 960 to 1,120 of each simulation. The range of

\footnotetext{
${ }^{9}$ Rondina (2013) conducts a similar exercise where the increase in foreign demand derives from international capital markets liberalization. It then shows that liberalization can lead to the emergence of asset price bubbles and, when they burst, to crises.
} 
variation between the 5 th and 95th percentiles provides information about the volatility of the economy at any point in time.
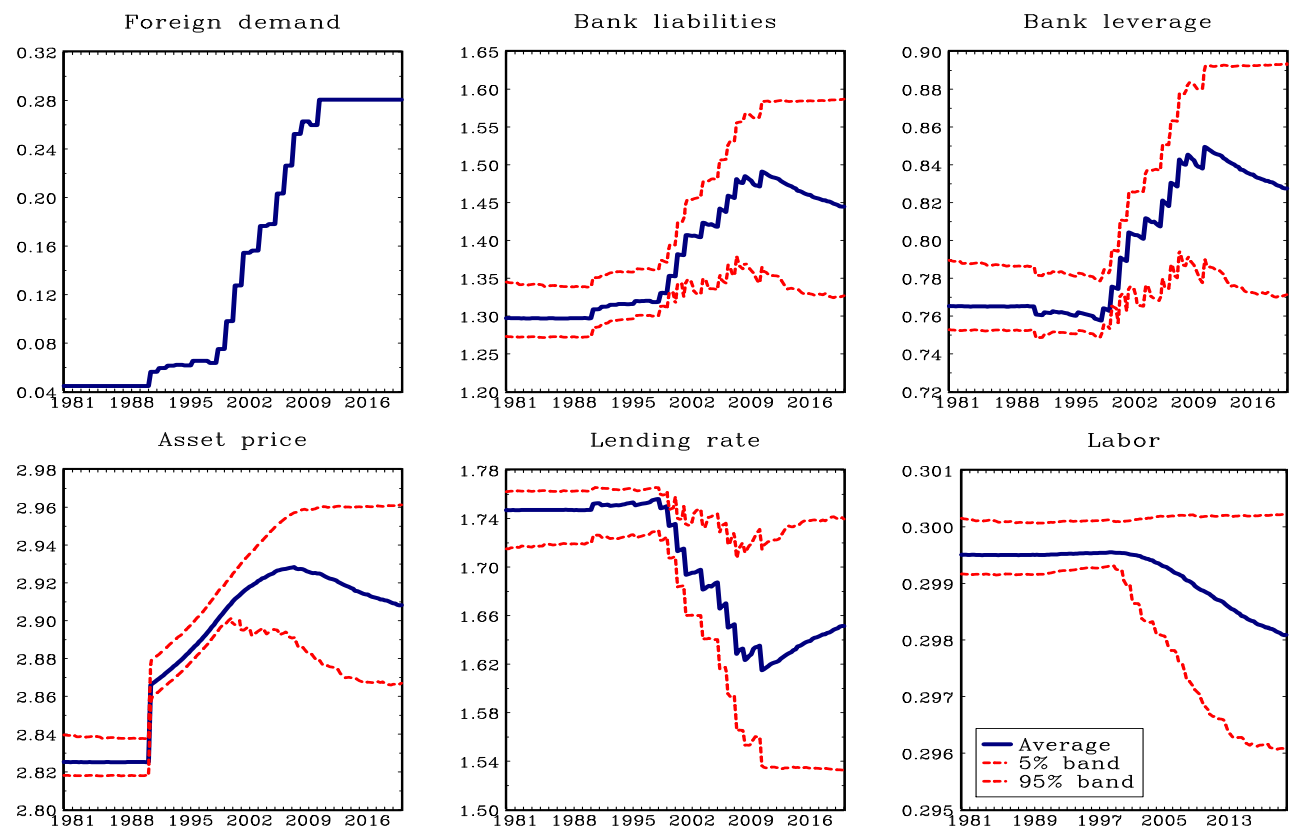

Figure 5: Change in foreign demand for bank liabilities. Responses of 1,000 simulations.

The first panel of Figure 5 plots the foreign demand for bank liabilities. The foreign demand is exogenous in the model and the 1991 change determines a structural break. The next five panels plot five endogenous variables: the total liabilities of banks (domestically and foreign owned), their leverage, the lending rate, the price of the fixed asset and the input of labor.

Following the increase in foreign demand, the interval delimited by the 5th and 95th percentiles of the repeated simulations widens dramatically. Therefore, financial and macroeconomic volatility increases substantially as we move to the 2000s. The probability of a bank crisis is always positive even before the structural break induced by the change in foreign demand for bank liabilities. However, after the increase in foreign demand for bank liabilities, the consequence of a crisis could be much bigger.

Besides the increase in financial and macroeconomic volatility, the figure reveals other interesting patterns. First, as the foreign demand increases, banks raise their leverage while the interest rate on loans decreases. The economy also experiences an increase in asset prices (the price of the fixed 
asset) but labor declines on average. This is a consequence of the decline in labor demand. As the foreign demand for bank liabilities increases, part of the increase is filled with lower holdings of bank liabilities by domestic entrepreneurs (in addition to higher bank leverage). But as domestic entrepreneurs hold less financial wealth, they become more averse to risk and hire less labor.

It is important to point out that, although labor falls in the average of all repeated simulations, the actual dynamics of labor during the 20 years that followed the 1991 break could be increasing or decreasing depending on the actual realizations of the sunspot shocks.

To show this point, I repeat the experiment shown in Figure 5 but for a particular sequence of sunspot shocks. More specifically, I simulate the model under the assumption that, starting in the first quarter of 1991, the economy experiences a sequence of draws of the sunspot variable $\varepsilon=1$ until the second quarter of 2008. Then in the third quarter of 2008 the draw of the sunspot becomes $\varepsilon=0$ but returns to $\varepsilon=1$ from the fourth quarter of 2008 and in all subsequent quarters. This captures the idea that expectations may have turned pessimistic in the fourth quarter of 2008 leading to a sudden financial and macroeconomic crisis. The resulting responses are plotted in Figure 6 by the continuous line.

The increase in demand for bank liabilities from the foreign sector induces a large increase in the leverage of banks. This is consistent with the evidence provided in Kalemli-Ozcana, Sorensen, and Yesiltas (2012). To the extent that the banking sector in the model is interpreted broadly and including all financial institutions, this paper shows that there has been a significant increase in the leverage of the banking sector prior to the sub-prime crisis, with the increase primarily driven by investment banks. Furthermore, even if the typical commercial banks did not show a significant increase in formal measures of leverage, they had significant off-balance sheet items, suggesting that they were also highly exposed to risk.

As long as the draw of the sunspot variable is $\varepsilon=1$, asset prices continue to increase and the input of labor expands. However, a single realization $\varepsilon=$ 0 of the sunspot variable can trigger a sizable decline in labor. Furthermore, even if the negative shock is only for one period and there are no crises afterwards, the recovery in the labor market is very slow. This is because the crisis generates a large decline in the financial wealth of employers and it takes a long time for them to rebuilt the lost wealth with savings.

Another way of showing the importance of the growth of emerging coun- 
Foreign demand

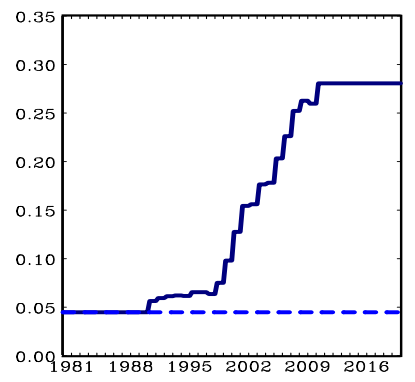

Asset price

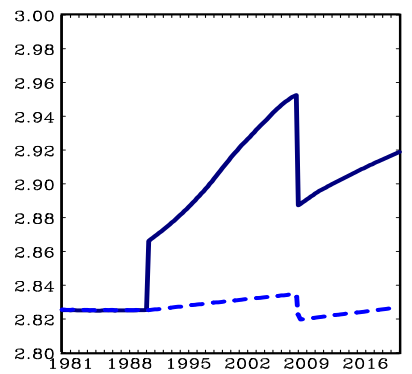

Bank liabilities

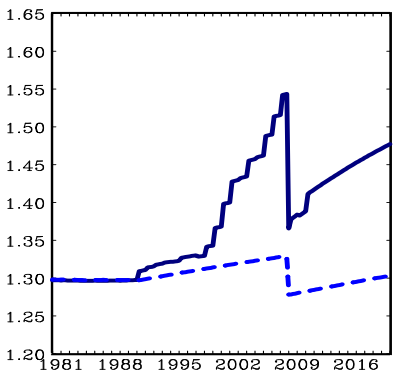

Lending rate

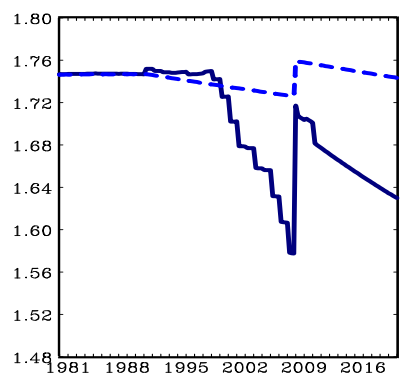

Bank leverage

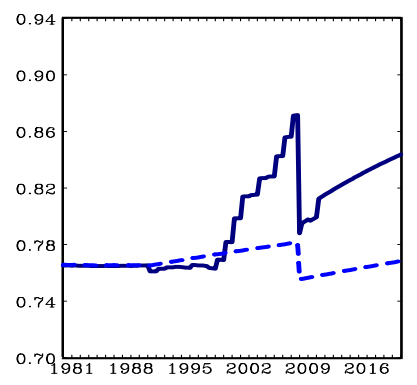

Labor

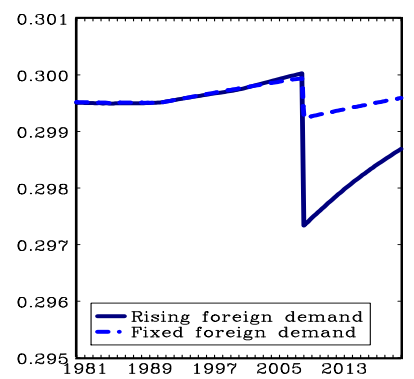

Figure 6: Responses of 1,000 simulations with same draws of the sunspot variable starting in 1991 with and without change in foreign demand for bank liabilities.

tries for macroeconomic stability in industrialized countries, is by conducting the following exercise. I repeat the simulation of the model in response to the same sequence of sunspot draws but under the assumption that the foreign demand for bank liabilities remains at the pre-1991 level for the whole simulation period. This counterfactual exercise tells us how the financial and macroeconomic dynamics in response to the same shocks would have changed in absence of the observed increase in foreign demand for bank liabilities. The resulting simulation is shown in Figure 6 by the dash line.

As can be seen, without the increase in foreign demand for bank liabilities, the same sequence of sunspot shocks would have generated a much smaller financial expansion before 2008 as well as a much smaller financial and macroeconomic contraction in the third quarter of 2008. Therefore, the increase in foreign demand for financial assets issued by industrialized countries could have contributed to the observed expansion of the financial sector in industrialized countries but it also created the conditions for greater financial and macroeconomic fragility that became evident once the crisis materialized. 
Although the re-adjustment in financial variables is quite large, the response of labor is not very big. The reason is because the decline in the demand of labor is counterbalanced by a reduction in the wage rate. However, if wages cannot fall because of downward rigidity, the response of labor would be much bigger.

To show this point, Figure 7 plots the simulation for the model with downward wage rigidities. As can be seen, the crisis induces a drop in labor that is more than 10 percent (continuous line). Without the growth of foreign demand for bank liabilities the drop in labor is also sizable but much smaller than in the case with higher foreign demand (dashed line). Therefore, the combination of higher leverages caused by the growing demand for bank liabilities together with downward wage rigidities could create the conditions for severe macroeconomic contractions in response to a banking crisis.
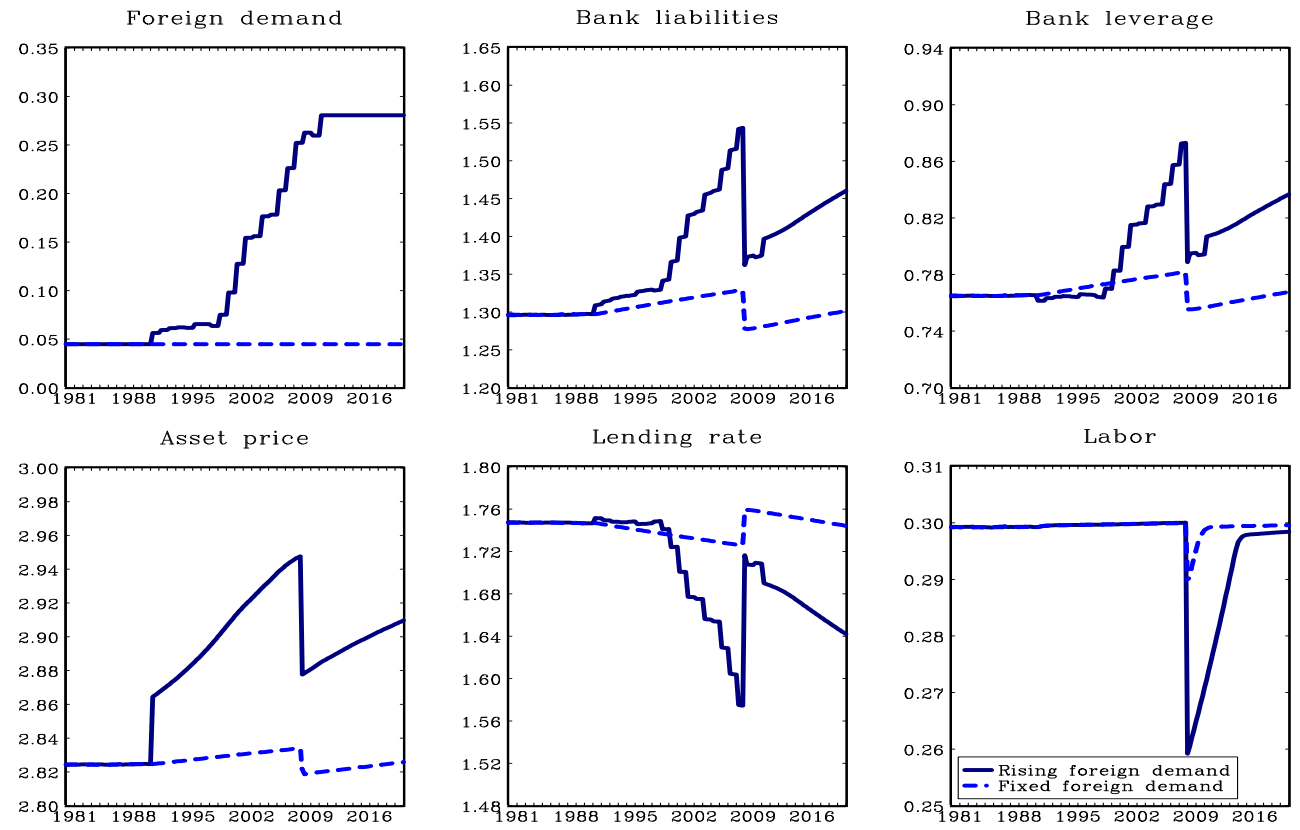

Figure 7: Model with downward wage rigidity. Responses of 1,000 simulations with same draws of the sunspot variable starting in 1991 with and without change in foreign demand for bank liabilities. 


\subsection{Financial innovations}

The financial sector has gone through a significant process of innovations. Some innovations were allowed by institutional liberalization while others followed from product and technological innovations. One way of thinking about financial innovations in the context of the model is to reduce the bank operation cost to raise funds, which is captured by the parameter $\tau$. The idea is that, thanks to financial liberalization and/or the introduction of new products and technologies, banks have been able to simplify their funding activity. In reduced form this is captured by a reduction in the parameter $\tau$.

From Proposition 2.3 we know that the cost $\tau$ determines the existence of multiple equilibria. For a sufficiently high $\tau$, the economy converges to a state with a unique equilibrium without crises. With a sufficiently low $\tau$, instead, the economy will eventually reaches a state with multiple equilibria. As a result, the economy experiences stochastic fluctuations where gradual booms are reversed by sudden crises. Therefore, as the operation $\operatorname{cost} \tau$ declines, the economy could move from a state where the equilibrium is unique to states with multiple equilibria.

Consider again the baseline parametrization of the model where $\tau=$ 0.0045 . With this parametrization, the economy is in states with multiple equilibria, and therefore, it experiences stochastic fluctuations in response to sunspot shocks. Now suppose that, starting in 1991, the cost decreases permanently to $\tau=0.0035$. The choice of 1991 for the structural break is only for illustrative purposes. Figure 8 shows the simulation statistics associated with the structural change in $\tau$. As for the analysis of the growing demand for bank liabilities, the change in $\tau$ is unexpected.

Starting in 1991, the distance between the 5th and 95th percentiles increases for all endogenous variables. Therefore, the decline in $\tau$ increases financial and macroeconomic volatility. On average, the economic experiences an expansion characterized by higher banking leverage and higher employment.

Figure 9 is constructed using the same methodology used in Figure 6, that is, starting in 1991 the economy experiences a sequence of sunspot draws $\varepsilon=1$, except in the third quarter of 2008. In the graph shown here, however, the 1991 structural break is the change in $\tau$ rather than the change in foreign demand for bank liabilities. As long as the draws of the sunspot variable are $\varepsilon=1$, the economy experiences financial and macroeconomic booms. However, a single reversal of the sunspot variable to $\varepsilon=0$ generates a persistent 
Intermediation cost

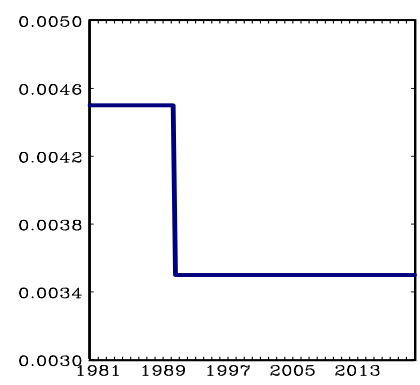

Asset price

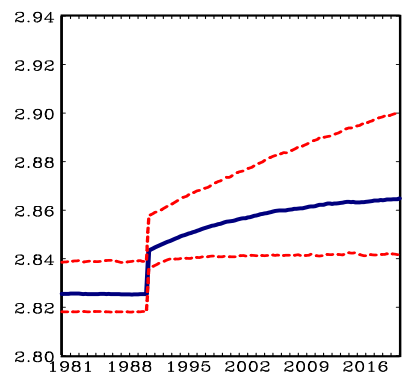

Bank liabilities

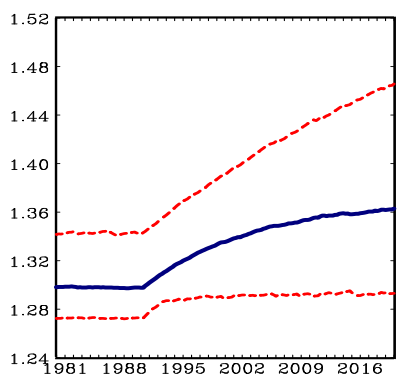

Lending rate

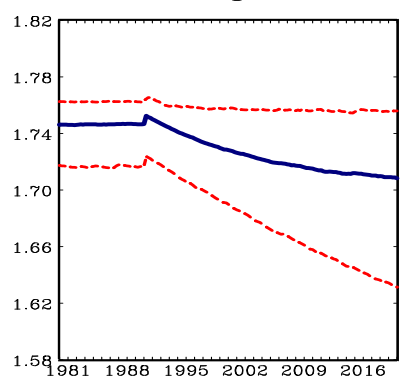

Bank leverage

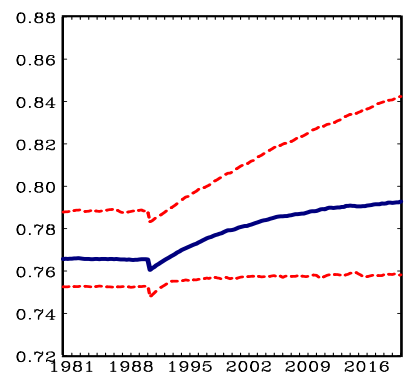

Labor

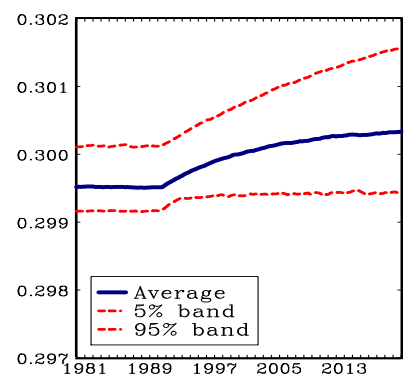

Figure 8: Change in bank operation cost $\tau$. Responses of 1,000 simulations.

downturn.

The dashed line shows the impulse responses to the same sequence of sunspot draws but under the assumption that $\tau$ does not change. As can be seen, the economy experiences a smaller financial and macroeconomic expansion before 2008 as well as a smaller contraction in the third quarter of 2008. Therefore, financial innovations could have contributed to the observed expansion of the financial sector in industrialized countries but it also created the conditions for greater financial and macroeconomic fragility that became evident once the crisis materialized. Finally, Figure 10 shows that the implications of the crisis for the labor market are much bigger if wages are downward rigid.

\section{Conclusion}

The traditional role of banks is to facilitate the transfer of resources from agents in excess of funds to agents in need of funds. This paper emphasizes a second important role played by banks: the issuance of liabilities that can be held by the nonfinancial sector for insurance purposes. This is similar 
Intermediation cost

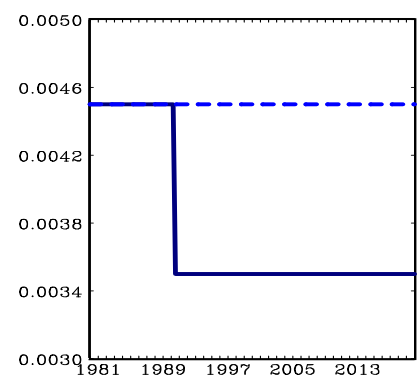

Asset price

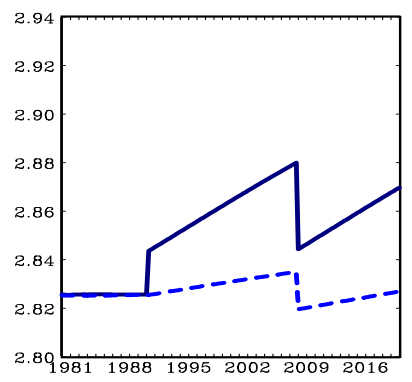

Bank liabilities

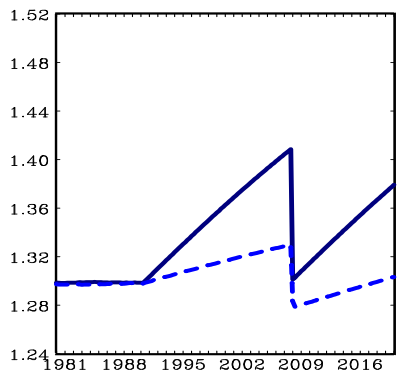

Lending rate

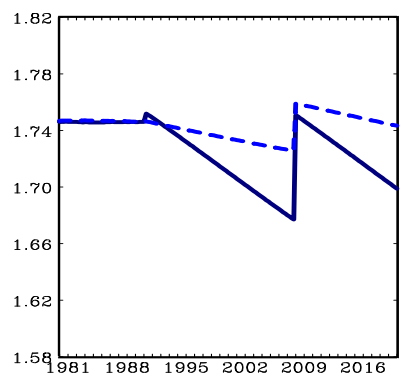

Bank leverage

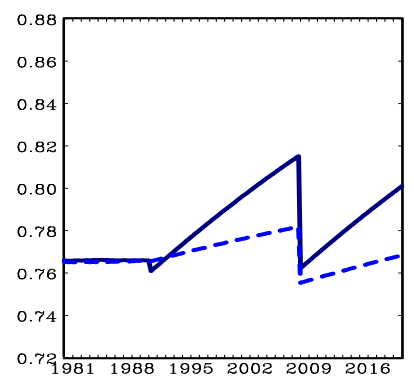

Labor

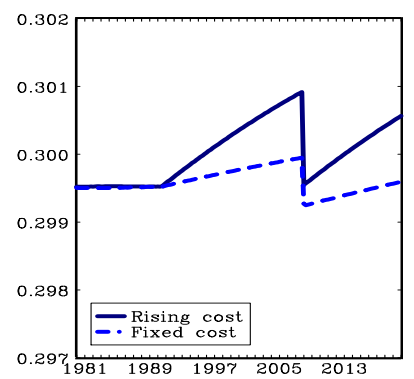

Figure 9: Responses of 1,000 simulations with same draws of the sunspot variable starting in 1991, with and without change in the operation $\operatorname{cost} \tau$.

to the role of banks in creating liabilities that can be used for transaction as in Williamson (2012). The difference is that in the current paper bank liabilities are valued not for their use as a mean of exchange but as an insurance instrument. When the stock of bank liabilities or their value are low, agents are less willing to engage in risky economic activities and this causes a macroeconomic downturn.

The paper also shows that booms and busts in financial intermediation can be driven by self-fulfilling expectations about the liquidity of banks. When the economy expects the banking sector to be liquid, banks have an incentive to leverage and this generates a macroeconomic boom. But as the leverage increases, the banking sector becomes vulnerable to pessimistic expectations that could generate self-fulfilling liquidity crises.

The model has been used to study two recent trends: the growth of emerging economies and financial innovations. Both trends have contributed to a macroeconomic expansion in industrialized countries but they have also increased the potential instability of the macroeconomic system. As long as expectations remain optimistic, countries experience a macroeconomic 
Intermediation cost

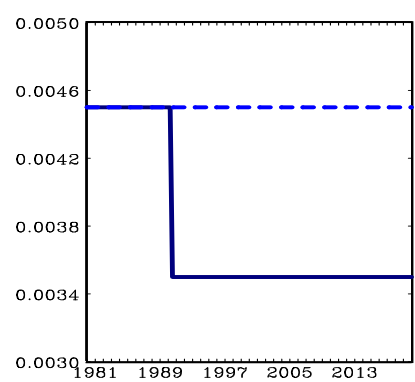

Asset price

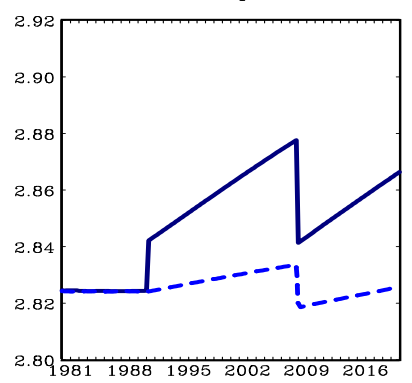

Bank liabilities

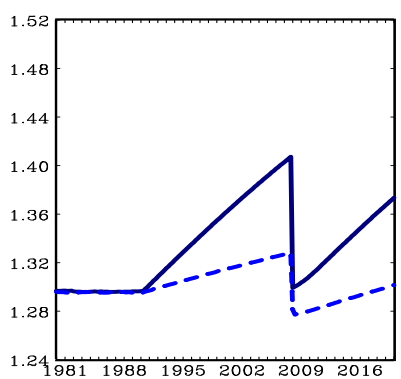

Lending rate

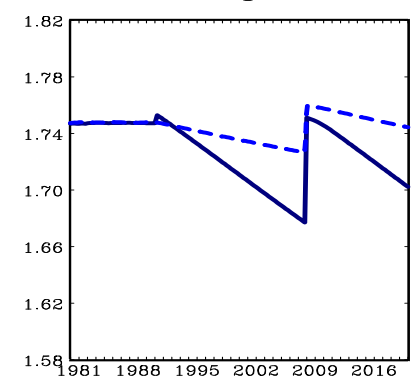

Bank leverage

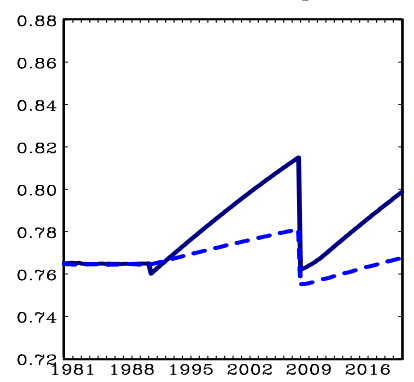

Labor

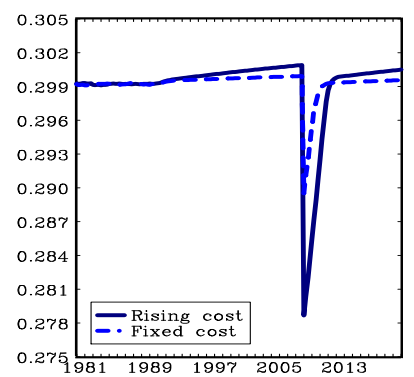

Figure 10: Model with downward wage rigidity. Responses of 1,000 simulations with same draws of the sunspot variable starting in 1991, with and without change in the operation $\operatorname{cost} \tau$.

boom. However, when expectations turn pessimistic, the economy experiences deeper macroeconomic contractions. 


\section{Appendix}

\section{A Proof of Lemma 2.1}

The optimization problem of an entrepreneur can be written recursively as

$$
\begin{aligned}
V_{t}\left(b_{t}\right)= & \max _{h_{t}} \mathbb{E}_{t} \tilde{V}_{t}\left(a_{t}\right) \\
& \text { subject to } \\
& a_{t}=b_{t}+\left(z_{t}-w_{t}\right) h_{t} \\
\tilde{V}_{t}\left(a_{t}\right)= & \max _{b_{t+1}}\left\{\ln \left(c_{t}\right)+\beta \mathbb{E}_{t} V_{t+1}\left(b_{t+1}\right)\right\} \\
& \text { subject to } \\
& c_{t}=a_{t}-\frac{b_{t+1}}{R_{t}}
\end{aligned}
$$

Since the information set changes from the beginning of the period to the end of the period, the optimization problem has been separated according to the available information. In sub-problem (20) the entrepreneur chooses the input of labor without knowing the productivity $z_{t}$. In sub-problem (21) the entrepreneur allocates the end of period wealth in consumption and savings after observing $z_{t}$.

The first order condition for sub-problem (20) is

$$
\mathbb{E}_{t} \frac{\partial \tilde{V}_{t}}{\partial a_{t}}\left(z_{t}-w_{t}\right)=0
$$

The envelope condition from sub-problem (21) gives

$$
\frac{\partial \tilde{V}_{t}}{\partial a_{t}}=\frac{1}{c_{t}}
$$

Substituting in the first order condition we obtain

$$
\mathbb{E}_{t}\left(\frac{z_{t}-w_{t}}{c_{t}}\right)=0
$$

At this point we proceed by guessing and verifying the optimal policies for employment and savings. The guessed policies take the form:

$$
\begin{aligned}
h_{t} & =\phi_{t} b_{t} \\
c_{t} & =(1-\beta) a_{t}
\end{aligned}
$$


Since $a_{t}=b_{t}+\left(z_{t}-w_{t}\right) h_{t}$ and the employment policy is $h_{t}=\phi_{t} b_{t}$, the end of period wealth can be written as $a_{t}=\left[1+\left(z_{t}-w_{t}\right) \phi_{t}\right] b_{t}$. Substituting in the guessed consumption policy we obtain

$$
c_{t}=(1-\beta)\left[1+\left(z_{t}-w_{t}\right) \phi_{t}\right] b_{t} .
$$

This expression is used to replace $c_{t}$ in the first order condition (22) to obtain

$$
\mathbb{E}_{t}\left[\frac{z_{t}-w_{t}}{1+\left(z_{t}-w_{t}\right) \phi_{t}}\right]=0
$$

which is the condition stated in Lemma 2.1.

To complete the proof, we need to show that the guessed policies (23) and (24) satisfy the optimality condition for the choice of consumption and saving. This is characterized by the first order condition of sub-problem (21), which is equal to

$$
-\frac{1}{c_{t} R_{t}}+\beta \mathbb{E}_{t} \frac{\partial V_{t+1}}{\partial b_{t+1}}=0 .
$$

From sub-problem (20) we derive the envelope condition $\partial V_{t} / \partial b_{t}=1 / c_{t}$ which can be used in the first order condition to obtain

$$
\frac{1}{c_{t}}=\beta R_{t} \mathbb{E}_{t} \frac{1}{c_{t+1}}
$$

We have to verify that the guessed policies satisfy this condition. Using the guessed policy (24) and equation (25) updated one period, the first order condition can be rewritten as

$$
\frac{1}{a_{t}}=\beta R_{t} \mathbb{E}_{t} \frac{1}{\left[1+\left(z_{t+1}-w_{t+1}\right) \phi_{t+1}\right] b_{t+1}} .
$$

Using the guessed policy (24) we have that $b_{t+1}=\beta R_{t} a_{t}$. Substituting and rearranging we obtain

$$
1=\mathbb{E}_{t}\left[\frac{1}{1+\left(z_{t+1}-w_{t+1}\right) \phi_{t+1}}\right] .
$$

The final step is to show that, if condition (26) is satisfied, then condition (27) is also satisfied. Let's start with condition (26), updated by one period. Multiplying both sides by $\phi_{t+1}$ and then subtracting 1 in both sides we obtain

$$
\mathbb{E}_{t+1}\left[\frac{\left(z_{t+1}-w_{t+1}\right) \phi_{t+1}}{1+\left(z_{t+1}-w_{t+1}\right) \phi_{t+1}}-1\right]=-1
$$

Multiplying both sides by -1 and taking expectations at time $t$ we obtain (27). 


\section{B Proof of Proposition 2.1}

As shown in Lemma 2.1, the optimal saving of entrepreneurs takes the form $b_{t+1}^{i} / R_{t}^{b}=\beta a_{t}^{i}$, where $a_{t}^{i}$ is the end-of-period wealth $a_{t}^{i}=b_{t}^{i}+\left(z_{t}^{i}-w_{t}\right) h_{t}^{i}$. Since $h_{t}^{i}=\phi\left(w_{t}\right) b_{t}^{i}$ (see Lemma 2.1), the end-of-period wealth can be rewritten as $a_{t}^{i}=\left[1+\left(z_{t}^{i}-w_{t}\right) \phi\left(w_{t}\right)\right] b_{t}^{i}$. Substituting into the optimal saving and aggregating over all entrepreneurs we obtain

$$
B_{t+1}=\beta R_{t}^{b}\left[1+\left(\bar{z}-w_{t}\right) \phi\left(w_{t}\right)\right] B_{t} .
$$

This equation defines the aggregate demand for bonds as a function of the interest rate $R_{t}^{b}$, the wage rate $w_{t}$, and the beginning-of-period aggregate wealth of entrepreneurs $B_{t}$. Notice that the term in square brackets is bigger than 1 . Therefore, in a steady state equilibrium where $B_{t+1}=B_{t}$, the condition $\beta R<1$ must be satisfied.

Using the equilibrium condition in the labor market, I can express the wage rate as a function of $B_{t}$. In particular, equalizing the demand for labor, $H_{t}^{D}=\phi\left(w_{t}\right) \tilde{B}_{t}$, to the supply from workers, $H_{t}^{S}=\left(w_{t} / \alpha\right)^{\nu}$, the wage $w_{t}$ can be expressed as a function of only $\tilde{B}_{t}$. We can then use this function to replace $w_{t}$ in (28) and express the demand for bank liabilities as a function of only $B_{t}$ and $R_{t}^{b}$ as follows

$$
B_{t+1}=s\left(B_{t}\right) R_{t}^{b}
$$

The function $s\left(B_{t}\right)$ is strictly increasing in the wealth of entrepreneurs, $B_{t}$.

Consider now the supply of bonds from workers. For simplicity I assume that the borrowing constraint takes the form specified in equation (2), that is, $l_{t+1} \leq \eta$. Using this limit together with the first order condition (5), we have that, either the interest rate satisfies $1=\beta R_{t}^{b}$ or workers are financially constrained, that is, $B_{t+1}=\eta$. When the interest rate is equal to the inter-temporal discount rate (first case), we can see from (28) that $B_{t+1}>B_{t}$. So eventually, the borrowing constraint of workers becomes binding, that is, $B_{t+1}=\eta$ (second case). When the borrowing constraint is binding, the multiplier $\mu_{t}$ is positive and condition (5) implies that the interest rate is smaller than the inter-temporal discount rate. So the economy has reached a steady state. The steady state interest rate is determined by condition (29) after setting $B_{t}=B_{t+1}=\eta$. This is the only steady state equilibrium.

When the borrowing constraint takes the form (3), the proof is more involved but the economy also reaches a steady state with $\beta R<1$. 


\section{First order conditions for workers}

The optimization problem of a worker can be written recursively as

$$
\begin{aligned}
V_{t}\left(l_{t}, k_{t}\right)= & \max _{h_{t}, l_{t+1}, k_{t+1}}\left\{c_{t}-\alpha \frac{h_{t}^{1+\frac{1}{\nu}}}{1+\frac{1}{\nu}}+\beta V_{t+1}\left(l_{t+1}, k_{t+1}\right)\right\} \\
& \text { subject to } \\
& c_{t}=w_{t} h_{t}+\chi k_{t}+\frac{l_{t+1}}{R_{t}^{l}}-l_{t}-\left(k_{t+1}-k_{t}\right) p_{t} \\
& \eta \geq l_{t+1} .
\end{aligned}
$$

Given $\beta \mu_{t}$ the lagrange multiplier associated with the borrowing constraint, the first order conditions with respect to $h_{t}, l_{t+1}, k_{t+1}$ are, respectively,

$$
\begin{aligned}
& -\alpha h_{t}^{\frac{1}{\nu}}+w_{t}=0, \\
& \frac{1}{R_{t}^{l}}+\beta \frac{\partial V_{t+1}\left(l_{t+1}, k_{t+1}\right.}{\partial l_{t+1}}-\beta \mu_{t}=0, \\
& -p_{t}+\beta \frac{\partial V_{t+1}\left(l_{t+1}, k_{t+1}\right.}{\partial k_{t+1}}=0 .
\end{aligned}
$$

The envelope conditions are

$$
\begin{aligned}
& \frac{\partial V_{t}\left(l_{t+1}, k_{t+1}\right.}{\partial l_{t+1}}=-1, \\
& \frac{\partial V_{t}\left(l_{t+1}, k_{t+1}\right.}{\partial k_{t+1}}=\chi+p_{t} .
\end{aligned}
$$

Updating by one period and substituting in the first order conditions we obtain (4), (5), (6).

When the borrowing constraint takes the form $\eta \mathbb{E}_{t} p_{t+1} k_{t+1} \geq l_{t+1}$, the first order condition with respect to $k_{t+1}$ becomes

$$
-p_{t}+\beta \frac{\partial V_{t+1}\left(l_{t+1}, k_{t+1}\right.}{\partial k_{t+1}}+\eta \beta \mu_{t} \mathbb{E}_{t} p_{t+1}=0,
$$

Substituting the envelope condition we obtain (7). 


\section{First order conditions for problem (12)}

The first order conditions for problem (12) with respect to $b_{t+1}$ and $l_{t+1}$ are

$$
\begin{aligned}
\frac{1-\tau}{\bar{R}_{t}^{b}} \mathbb{E}_{t} \frac{\partial \tilde{b}_{t+1}}{\partial b_{t+1}} & =\beta \mathbb{E}_{t}\left[\frac{\partial \tilde{b}_{t+1}}{\partial b_{t+1}}+\frac{\partial \tilde{\varphi}_{t+1}}{\partial b_{t+1}}+\gamma_{t}\right] \\
\frac{1}{R_{t}^{l}} & =\frac{1-\tau}{\bar{R}_{t}^{b}} \mathbb{E}_{t} \frac{\partial \tilde{b}_{t+1}}{\partial l_{t+1}}+\beta \mathbb{E}_{t}\left[1-\frac{\partial \tilde{b}_{t+1}}{\partial l_{t+1}}-\frac{\partial \tilde{\varphi}_{t+1}}{\partial l_{t+1}}+\gamma_{t}\right],
\end{aligned}
$$

where $\gamma_{t}$ is the Lagrange multiplier associated with constraint $b_{t+1} \leq l_{t+1}$.

I now use the definition of $\tilde{b}_{t+1}$ and $\tilde{\varphi}_{t+1}$ provided in equations (8) and (9) to derive the following terms

$$
\begin{aligned}
\mathbb{E}_{t} \frac{\partial \tilde{b}_{t+1}}{\partial b_{t+1}} & =1-\theta\left(\omega_{t+1}\right), \\
\mathbb{E}_{t} \frac{\partial \tilde{b}_{t+1}}{\partial l_{t+1}} & =\theta\left(\omega_{t+1}\right) \underline{\xi} \\
\mathbb{E}_{t} \frac{\partial \tilde{\varphi}_{t+1}}{\partial b_{t+1}} & =\theta\left(\omega_{t+1}\right)\left[\varphi^{\prime}\left(\omega_{t+1}-\underline{\xi}\right) \omega_{t+1}+\varphi\left(\omega_{t+1}-\underline{\xi}\right)\right], \\
\mathbb{E}_{t} \frac{\partial \tilde{\varphi}_{t+1}}{\partial l_{t+1}} & =-\theta\left(\omega_{t+1}\right) \varphi^{\prime}\left(\omega_{t+1}-\underline{\xi}\right) \omega_{t+1}^{2},
\end{aligned}
$$

where $\theta\left(\omega_{t+1}\right)$ is the probability of renegotiation defined as

$$
\theta\left(\omega_{t+1}\right)= \begin{cases}0, & \text { if } \quad \omega_{t+1}<\underline{\xi} \\ \lambda, & \text { if } \quad \underline{\xi} \leq \omega_{t+1} \leq 1 \\ 1, & \text { if } \quad \omega_{t+1}>1\end{cases}
$$

Substituting in (30) and (31) and re-arranging we obtain

$$
\begin{aligned}
\frac{1-\tau}{\bar{R}_{t}^{b}} & =\beta\left[1+\frac{\theta\left(\omega_{t+1}\right)\left(\varphi^{\prime}\left(\omega_{t+1}-\underline{\xi}\right) \omega_{t+1}+\varphi\left(\omega_{t+1}-\underline{\xi}\right)\right)+\gamma_{t}}{1-\theta\left(\omega_{t+1}\right)}\right] \\
\frac{1}{R_{t}^{l}} & =\beta\left[1+\theta\left(\omega_{t+1}\right) \varphi^{\prime}\left(\omega_{t+1}-\underline{\xi}\right) \omega_{t+1}^{2}+\left(\frac{1-\tau}{\beta \bar{R}_{t}^{b}}-1\right) \theta\left(\omega_{t+1}\right) \underline{\xi}+\gamma_{t}\right]
\end{aligned}
$$

where the multiplier $\gamma_{t}$ is zero if $\omega_{t+1}<1$ and positive if $\omega_{t+1}=1$. Eliminating $\gamma_{t}$ we obtain (13) and (14) with can be satisfied with the inequality sign if $\gamma_{t}>0$. 


\section{E $\quad$ Proof of Lemma 2.2}

Let's consider the first order conditions (32) and (33). When $\omega_{t+1}<\underline{\xi}$, the default probability is $\theta\left(\omega_{t+1}\right)=0$ and the first order conditions are satisfied with equality. Therefore, they simplify to

$$
\begin{aligned}
\frac{1-\tau}{\bar{R}_{t}^{b}} & =\beta, \\
\frac{1}{R_{t}^{l}} & =\beta,
\end{aligned}
$$

which proves the first part of the lemma.

Now suppose that $\omega_{t+1}>\underline{\xi}$. In this case the probability of default is $\theta\left(\omega_{t+1}\right)=$ $\lambda$ and the first order conditions can be written as

$$
\begin{aligned}
\frac{1-\tau}{\bar{R}_{t}^{b}} & =\beta\left[1+\frac{\lambda \varphi^{\prime}\left(\omega_{t+1}-\underline{\xi}\right) \omega_{t+1}+\lambda \varphi\left(\omega_{t+1}-\underline{\xi}\right)+\gamma_{t}}{1-\lambda}\right], \\
\frac{1}{R_{t}^{l}} & =\beta\left[1+\lambda \varphi^{\prime}\left(\omega_{t+1}-\underline{\xi}\right) \omega_{t+1}^{2}+\lambda \underline{\xi}\left(\frac{1-\tau}{\beta \bar{R}_{t}^{b}}-1\right)+\gamma_{t}\right],
\end{aligned}
$$

where the multiplier $\gamma_{t}$ is bigger than zero if $\omega_{t+1}=1$.

That $\bar{R}_{t}^{b} /(1-\tau)$ and $R_{t}^{l}$ are both smaller than $1 / \beta$ is obvious from the above two conditions. What is not immediate to see is that $\bar{R}_{t}^{b} /(1-\tau)<R_{t}^{l}$. To show this, let's first use equation (34) to eliminate $\bar{R}_{t}^{b}$ in equation (35). After some re-arrangement I can rewrite equation (35) as

$$
\frac{1}{R_{t}^{l}}=\beta\left[1+\frac{\lambda \varphi^{\prime}\left(\omega_{t+1}-\underline{\xi}\right) \omega_{t+1} \mathbf{K}_{1}+\lambda \varphi\left(\omega_{t+1}-\underline{\xi}\right) \mathbf{K}_{\mathbf{2}}+\gamma_{t} \mathbf{K}_{3}}{1-\lambda}\right],
$$

where

$$
\begin{aligned}
& \mathbf{K}_{1}=(1-\lambda) \omega_{t+1}+\lambda \underline{\xi}, \\
& \mathbf{K}_{2}=\lambda \underline{\xi}, \\
& \mathbf{K}_{3}=1-\lambda+\lambda \underline{\xi} .
\end{aligned}
$$

Because $\omega_{t+1}, \underline{\xi}$ and $\lambda$ are all smaller than 1 , the terms $\mathbf{K}_{1}, \mathbf{K}_{2}$ and $\mathbf{K}_{3}$ are also smaller than 1 .

To prove that $\bar{R}_{t}^{b} /(1-\tau)<R_{t}^{l}$ I need to show that the right-hand-side of (34) is bigger than the right-hand-side of (36). This requires to show that

$$
\begin{aligned}
& \lambda \varphi^{\prime}\left(\omega_{t+1}-\underline{\xi}\right) \omega_{t+1}+\lambda \varphi\left(\omega_{t+1}-\underline{\xi}\right)+\gamma_{t}> \\
& \lambda \varphi^{\prime}\left(\omega_{t+1}-\underline{\xi}\right) \omega_{t+1} \mathbf{K}_{\mathbf{1}}+\lambda \varphi\left(\omega_{t+1}-\underline{\xi}\right) \mathbf{K}_{\mathbf{2}}+\gamma_{t} \mathbf{K}_{3} .
\end{aligned}
$$

This follows directly from $\mathbf{K}_{1}, \mathbf{K}_{2}$ and $\mathbf{K}_{3}$ being smaller than 1 . 


\section{F $\quad$ Proof of Proposition 2.2}

Banks make decisions at two different stages. At the beginning of the period they choose whether to renegotiate the debt and at the end of the period they choose the funding and lending policies. Given the initial states, $b_{t}$ and $l_{t}$, the renegotiation decision boils down to a take-it or leave-it offer made by each bank to its creditors for the repayment of the debt. Denote by $\tilde{b}_{t}=f\left(b_{t}, l_{t}, \xi_{t}^{e}\right)$ the offered repayment. This depends on the individual liabilities $b_{t}$, individual assets $l_{t}$, and the expected liquidation price of assets $\xi_{t}^{e}$. The superscript $e$ is to make clear that the bank decision depends on the expected price in the eventuality of liquidation. Obviously, the best repayment offer made by the bank is

$$
f\left(b_{t}, l_{t}, \xi_{t}^{e}\right)=\left\{\begin{array}{ll}
b_{t}, & \text { if } \quad b_{t} \leq \xi_{t}^{e} l_{t} \\
\xi_{t}^{e} l_{t}, & \text { if } \quad b_{t}>\xi_{t}^{e} l_{t}
\end{array},\right.
$$

which is accepted by creditors whenever the actual liquidation price is bigger than the expected price $\xi_{t}^{e}$.

After the renegotiation stage, banks choose the funding and lending policies, $b_{t+1}$ and $l_{t+1}$. These policies depend on the two interest rates, $\bar{R}_{t}^{b}$ and $R_{l}$, and on the probability distribution of the next period liquidation price $\xi_{t+1}$. Since we could have multiple equilibria, the next period price could be stochastic. Suppose that the price could take two values, $\underline{\xi}$ and 1 , with the probability of the low value defined as

$$
\theta\left(\omega_{t+1}\right)= \begin{cases}0, & \text { if } \quad \omega_{t+1}<\underline{\xi} \\ \lambda, & \text { if } \quad \underline{\xi} \leq \omega_{t+1} \leq 1 \\ 1, & \text { if } \quad \omega_{t+1}>1 .\end{cases}
$$

The variable $\omega_{t+1}=b_{t+1} / l_{t+1}$ represents the leverage of all banks in a symmetric equilibrium, that is, they all choose the same leverage. For the moment the symmetry of the equilibrium is an assumption. I will then show below that in fact banks do not have incentives to deviate from the leverage chosen by other banks.

Given the above assumption about the probability distribution of the liquidation price, the funding and lending policies of the bank are characterized in Lemma 2.2 and depend on $\bar{R}_{t}^{b}$ and $R_{t}^{l}$. In short, if $\bar{R}_{t}^{b} /(1-\tau)=R_{t}^{l}$, then the optimal policy of the bank is to choose a leverage $\omega_{t+1} \leq \underline{\xi}$. If $\bar{R}_{t}^{b} /(1-\tau)<R_{t}^{l}$, the optimal leverage is $\omega_{t+1}>\xi$.

Given the assumption that the equilibrium is symmetric (all banks choose the same leverage $\left.\omega_{t+1}\right)$, multiple equilibria arise if the chosen leverage is $\omega_{t+1} \in\{\underline{\xi}, 1\}$. 
In fact, once we move to the next period, if the market expects $\xi_{t+1}^{e}=\underline{\xi}$, all banks are illiquid and they choose to renege on their liabilities (given the renegotiation policy (37)). As a result, there will not be any bank that can buy the liquidated assets of other banks. Then the only possible price that is consistent with the expected price is $\xi_{t+1}=\underline{\xi}$. On the other hand, if the market expects $\xi_{t+1}^{e}=1$, banks are liquid and, if one bank reneges, creditors can sell the liquidated assets to other banks at the price $\xi_{t+1}=1$. Therefore, it is optimal for banks not to renegotiate consistently with the renegotiation policy (37).

The above proof, however, assumes that the equilibrium is symmetric, that is, all banks choose the same leverage. To complete the proof, we have to show that there is no incentive for an individual bank to deviate from the leverage chosen by other banks. In particular, I need to show that, in the anticipation that the next period liquidation price could be $\xi_{t+1}=\xi$, a bank do not find convenient to chose a lower leverage so that, in the eventuality that the next period price is $\xi_{t+1}=\xi$, the bank could purchase the liquidated asset at a price lower than 1 and make a profit (since the unit value for the bank of the liquidated assets is 1 .

If the price at $t+1$ is $\xi_{t+1}=\underline{\xi}$, a liquid bank could offer a price $\underline{\xi}+\epsilon$, where $\epsilon$ is a small but positive number. Since the repayment offered by a defaulting bank is $\xi l_{t+1}$, creditors prefer to sell the assets rather than accepting the repayment offered by the defaulting bank. However, if this happens, the expectation of the liquidation price $\xi^{e}=\underline{\xi}$ turns out to be incorrect ex-post. Therefore, the presence of a single bank with liquidity will raise the expected liquidation price to $\underline{\xi}+\epsilon$. But even with this new expectation, a bank with liquidity can make a profit by offering $\underline{\xi}+2 \epsilon$. Again, this implies that the expectation turns out to be incorrect ex-post. This mechanism will continue to raise the expected price to $\xi_{t+1}^{e}=1$. At this point the liquid bank will not offer a price bigger than 1 and the ex-post liquidation price is correctly predicted to be 1 . Therefore, as long as there is a single bank with liquidity, the expected liquidation price must be 1 . But then a bank cannot make a profit in period $t+1$ by choosing a lower leverage in period $t$ with the goal of remaining liquid in the next period. This proves that there is no incentive to deviate from the policy chosen by other banks.

Finally, the fact that multiple equilibria cannot arise when $\omega_{t}<\underline{\xi}$ is obvious. Even if the price is $\underline{\xi}$, banks remain liquid.

\section{G Proof of Proposition 2.3}

Given a fixed interest rate $R^{b}$, the aggregate demand for bank liabilities, equation (16), has a converging fix point $B^{*}\left(R^{b}\right)$. The fixed point is increasing in $R^{b}$ and converges to infinity as $R^{b}$ converges to $1 / \beta$. This implies that, if $\tau=0$, then the leverage of banks is always bigger than $\underline{\xi}$. To show this, suppose that banks 
choose a leverage of $\omega<\underline{\xi}$. According to conditions (13) and (14), we have that $R^{b}=R^{l}=1 / \beta$. But when $R^{b}=1 / \beta$ the demand of bank liabilities is unbounded in the limit. This implies that to reach a stable equilibrium without renegotiation (that is, $\omega<\underline{\xi}$ ), $R^{b}$ must be smaller than $1 / \beta$. This requires $\tau$ to be sufficiently big. In fact, when $\tau>0$ and $\omega<\underline{\xi}$, we have $R^{b} /(1-\tau)=R^{l}=1 / \beta$. Since the demand for bank liabilities is increasing in $R^{b}$, there must be some $\hat{\tau}>0$ such that, for $\tau>\hat{\tau}$, the equilibrium is characterized by $\omega<\underline{\xi}$. This implies that the economy is not subject to crises and converges to a steady state. For $\tau<\hat{\tau}$, instead, the equilibrium is characterized by $\omega>\xi$. In this case the economy is subject to self-fulfilling crises and, therefore, it does not converge to a steady state.

\section{H Numerical solution}

I describe the numerical procedure to solve the model with the endogenous borrowing constraint specified in (3). I first describe the numerical procedure when the external demand for bank liabilities is fixed (without loss of generality set to zero). In this case I can solve for the stochastic stationary equilibrium. I will then describe the numerical procedure when the external demand for bank liabilities changes over time, inducing a transition dynamics.

\section{H.1 Stationary equilibrium without structural break}

The states of the economy are given by the bank liabilities $B_{t}$, the bank loans $L_{t}$ and the realization of the sunspot shock $\varepsilon_{t}$. These three variables are important in determining the renegotiation liabilities $\tilde{B}_{t}$. However, once we know the renegotiated liabilities $\tilde{B}_{t}$, this becomes the sufficient state for solving the model. Therefore, in the computation I will solve for the recursive equilibrium using $\tilde{B}_{t}$ as a state variable.

I will use the following equilibrium conditions:

$$
\begin{gathered}
H_{t}=\phi\left(w_{t}\right) \tilde{B}_{t}, \\
\frac{B_{t+1}}{R_{t}^{b}}=\beta A_{t}, \\
A_{t}=\tilde{B}_{t}+\left(1-w_{t}\right) H_{t} \\
\alpha H_{t}^{\frac{1}{\nu}}=w_{t}, \\
1=\beta R_{t}^{l}\left(1+\mu_{t}\right), \\
p_{t}=\beta \mathbb{E}_{t}\left[\chi+\left(1+\eta \mu_{t}\right) p_{t+1}\right],
\end{gathered}
$$




$$
\begin{aligned}
& L_{t+1}=\eta \mathbb{E}_{t} p_{t+1}, \\
& \frac{1-\tau}{\bar{R}_{t}^{b}} \geq \beta\left[1+\frac{\theta\left(\omega_{t+1}\right)\left(\varphi^{\prime}\left(\omega_{t+1}-\underline{\xi}\right) \omega_{t+1}+\varphi\left(\omega_{t+1}-\underline{\xi}\right)\right)}{1-\theta\left(\omega_{t+1}\right)}\right], \\
& \frac{1}{R_{t}^{l}} \geq \beta\left[1+\theta\left(\omega_{t+1}\right) \varphi^{\prime}\left(\omega_{t+1}-\underline{\xi}\right) \omega_{t+1}^{2}+\theta\left(\omega_{t+1}\right) \underline{\xi}\left(\frac{1-\tau}{\beta \bar{R}_{t}^{b}}-1\right)\right], \\
& \bar{R}_{t}^{b}=\left[1-\theta\left(\omega_{t+1}\right)+\theta\left(\omega_{t+1}\right)\left(\frac{\underline{\xi}}{\omega_{t+1}}\right)\right] R_{t}^{b}, \\
& \omega_{t+1}=\frac{B_{t+1}}{L_{t+1}}
\end{aligned}
$$

Equations (38)-(40) come from the aggregation of the optimal policies of entrepreneurs (labor demand, savings and end of periods wealth). Equations (41)(44) come from the optimization problem of workers (labor supply, optimal borrowing, optimal holding of the fixed asset, and borrowing constraint). Notice that the borrowing constraint of workers (equation (44) is not always binding. However, when it is not binding and the multiplier is $\mu_{t}=0$, workers' borrowing is not determined. Therefore, without loss of generality I assume that in this case workers borrow up to the limit. This explains why the borrowing constraint is always satisfied with equality. Equations (45)-(46) are the first order conditions of banks. These conditions are satisfied with equality if $\omega_{t+1}<1$ and with inequality if $\omega_{t+1}=1$. Equation (47) defines the expected return on bank liabilities given the price of these liabilities, that is, the inverse of $R_{t}^{b}$. The final equation (48) simply defines leverage.

One complication in solving this system of equations is that the expectation of the next period price of the fixed asset, $\mathbb{E}_{t} p_{t+1}$, is unknown. All we know is that the next period price is a function of $\tilde{B}_{t+1}$, that is, $p_{t+1}=P\left(\tilde{B}_{t+1}\right)$. If I knew the function $P\left(\tilde{B}_{t+1}\right)$, for any given state $\tilde{B}_{t}$, the above conditions would be a system of 11 equations in 11 variables: $H_{t}, A_{t}, \mu_{t}, w_{t}, p_{t}, R_{t}^{b}, R_{t}^{l}, \bar{R}_{t}^{b}, B_{t+1}, L_{t+1}$, $\omega_{t+1}$. Notice that $\tilde{B}_{t+1}$ is a known function of $B_{t+1}, L_{t+1}$ and the realization of the sunspot shock $\varepsilon$. Therefore, I can compute the expectation of the next period price $p_{t+1}$ if I know the function $P\left(\tilde{B}_{t+1}\right)$. We can then solve the 11 equations for the 11 variables and this would provide a solution for any given state $\tilde{B}_{t}$.

The problem is that I do not know the function $P\left(\tilde{B}_{t+1}\right)$. Therefore, the procedure will be based on a parametrization of an approximation of this function. In particular, I approximate $P\left(\tilde{B}_{t+1}\right)$ with a piece-wise linear function over a grid for the state variable $\tilde{B}_{t}$. I then solve the above system of equations at each grid point for $\tilde{B}_{t}$. As part of the solution I obtain the current price $p_{t}$. I then use the 
solution for the current price to update the approximated function $P\left(\tilde{B}_{t+1}\right)$ at the grid point. I repeat the iteration until convergence, that is, the values guessed for $P\left(\tilde{B}_{t+1}\right)$ at each grid point must be equal (up to a small rounding number) to the values of $p_{t}$ obtained by solving the model (given the guess for $P\left(\tilde{B}_{t+1}\right)$ ).

\section{H.2 Equilibrium with structural break}

When the external demand for bank liabilities changes over time or there are innovations that change the operation cost of banks, the economy transits from a stochastic equilibrium to a new stochastic equilibrium. This requires to solve for the transition and the solution method is based on the following steps.

1. I first compute the stochastic equilibrium under the regime that proceeds the structural break (the foreign demand for bank liabilities is constant at the initial level and/or the operation cost of banks is constant at the initial level).

2. I then compute the stochastic equilibrium under the terminal regime (the foreign demand of bank liabilities remains constant at the new level after the transition and/or the operation cost of banks remains constant at the new level).

3. At this point I solve the model backward at any time $t$ starting at the terminal period when the external demand and the operation cost remain constant at the new levels. At each $t$ I solve the system (38)-(48) using the approximated function $P_{t+1}\left(\tilde{B}_{t+1}\right)$ found at time $t+1$. In the first backward step (last period of the transition), $P_{t+1}\left(\tilde{B}_{t+1}\right)$ is the approximated price function found in the stochastic stationary equilibrium after the break (see previous computational step). 


\section{References}

Adrian, T., Colla, P., \& Shin, H. S. (2013). Which Financial Frictions? Parsing the Evidence from the Financial Crisis of 2007-9. In Acemoglu, D., Parker, J., \& Woodford, M. (Eds.), NBER Macroeconomics Annual 2012, pp. 159 - 214. MIT Press, Cambridge, Massachusetts.

Arellano, C., Bai, Y., \& Kehoe, P. (2011). Financial Markets and Fluctuations in Uncertainty. Research Department Staff Report, Federal Reserve Bank of Minneapolis.

Bernanke, B., \& Gertler, M. (1989). Agency Costs, Net Worth, and Business Fluctuations. American Economic Review, 79(1), 14-31.

Boissay, F., Collard, F., \& Smets, F. (2010). Booms and Systemic Banking Crises. Unpublished manuscript, European Central Bank.

Brunnermeier, M., \& Sannikov, Y. (2010). A Macroeconomic Model with a Financial Sector. Unpublished manuscript, Princeton University.

Caballero, R. J., Farhi, E., \& Gourinchas, P. O. (2008). An Equilibrium Model of Global Imbalances and Low Interest Rates. American Economic Review, 98(1), 358-93.

Cole, H. L., \& Kehoe, T. J. (2000). Self-Fulfilling Debt Crises. Review of Economic Studies, 67(1), 91-116.

Corbae, D., \& D'Erasmo, P. (2012). A Quantitative Model of Banking Industry DYnamics. Unpublished manuscript, University of Wisconsin and University of Maryland.

De Fiore, F., \& Uhlig, H. (2011). Bank Finance versus Bond Finance. Journal of Money Credit and Banking, 43(7), 1399-1421.

Eisfeldt, A., \& Muir, T. (2012). Aggregate Issuance and Savings Waves. Unpublished manuscript, Anderson School of Management, UCLA.

Gertler, M., \& Kiyotaki, N. (2010). Financial Intermediation and Credit Policy in Business Cycle Analysis. In Friedman, B. M., \& Woodford, M. (Eds.), Handbook of Monetary Economics, Vol. 3, chap. 11, pp. 1341-96. Elsevier, Amsterdam: Elsevier Science. 
Gertler, M., \& Karadi, P. (2011). A Model of Unconventional Monetary Policy. Journal of Monetary Economics, 58(1), 17-34.

Gourinchas, P. O., \& Rey, H. (2007). From World Banker to World Venture Capitalist: US External Adjustment and the Exorbitant Privilege. In Clarida, R. H. (Ed.), G7 Current Account Imbalances: Sustainability and Adjustment, pp. 11-66. The University of Chicago Press, Chicago, Illinois.

Holmstrom, B., \& Tirole, J. (1997). Financial Intermediation, Loanable Funds, and the Real Sector. Quarterly Journal of Economics, 112(3), 663-91.

Kalemli-Ozcana, S., Papaioannou, E., \& Perri, F. (2013). Global Banks and Crisis Transmission. Journal of International Economics, 89(2), 495-510.

Kalemli-Ozcana, S., Sorensen, B., \& Yesiltas, S. (2012). Leverage Across Firms, Banks, and Countries. Journal of International Economics, 88(2), 284-298.

Kiyotaki, N., \& Moore, J. H. (1997). Credit Cycles. Journal of Political Economy, 105(2), 211-48.

Lane, P. R., \& Milesi-Ferretti, G. M. (2007). The External Wealth of Nations Mark II: Revised and Extended Estimates of Foreign Assets and Liabilities, 1970-2004. Journal of International Economics, 73(2), 223-250.

Meh, C. A., \& Moran, K. (2010). The Role of Bank Capital in the Propagation of Shocks. Journal of Economic Dynamics and Control, 34(3), $555-76$.

Mendoza, E., Quadrini, V., \& Ríos-Rull, J. V. (2009). Financial Integration, Financial Development and Global Imbalances. Journal of Political Economy, 117(3), 297-323.

Mendoza, E., \& Quadrini, V. (2010). Financial Globalization, Financial Crises and Contagion. Journal of Monetary Economics, 57(1), 24-39.

Perri, F., \& Quadrini, V. (2011). International Recessions. NBER Working Paper No. 17201. 
Rampini, A., \& Viswanathan, S. (2012). Financial Intermediary Capital. Unpublished manuscript, Duke University.

Rondina, G. (2013). Non-Fundamental Dynamics and Financial Markets Integration. Unpublished manuscript, University of California, San Diego.

Shourideh, A., \& Zetlin-Jones, A. (2012). External Financing and the Role of Financial Frictions over the Business Cycle: Measurement and Theory. Unpublished manuscript, Wharton School.

Van den Heuvel, S. J. (2008). The Welfare Cost of Bank Capital Requirements. Journal of Monetary Economics, 55(2), 298-320.

Williamson, S. D. (2012). Liquidity, Monetary Policy, and the Financial Crisis: A New Monetarist Approach. American Economic Review, 102(6), 2570-2605. 